\author{
UNIVERSIDADE DE SÃO PAULO \\ FACULDADE DE MEDICINA DE RIBEIRÃO PRETO
}

RAQUEL VERCEZE BORTOLIEIRO

Caracterização do desempenho ocupacional de mulheres portadoras de dor pélvica crônica

Ribeirão Preto

-2015 - 


\title{
RAQUEL VERCEZE BORTOLIEIRO
}

Caracterização do desempenho ocupacional de mulheres portadoras de dor pélvica crônica

\author{
Dissertação a fim de obtenção do título de \\ Mestre pela Faculdade de Medicina de Ribeirão \\ Preto da Universidade de São Paulo. \\ Área de Concentração: Ginecologia e \\ Obstetrícia
}

Orientador: Prof. Dr. OmeroBenedicto Poli Neto

Ribeirão Preto 
AUTORIZO A REPRODUÇÃO E DIVULGAÇÃO TOTAL OU PARCIAL DESTE TRABALHO, POR QUALQUER MEIO CONVENCIONAL OU ELETRÔNICO, PARA FINS DE ESTUDO E PESQUISA, DESDE QUE CITADA A FONTE.

Ficha Catalográfica

Bortolieiro, Raquel Verceze

Caracterização do desempenho ocupacional de mulheres portadoras de dor pélvica crônica.

Ribeirão Preto - 2015. 75. pp.: Il.; 30cm

Dissertação de mestrado apresentada à Faculdade de Medicina de Ribeirão Preto da Universidade de São Paulo/USP - Área de Concentração: Ginecologia e Obstetrícia, opção Biologia da Reprodução.

Orientador: Poli Neto, Omero Benedicto

1. Dor Pélvica Crônica, 2. Terapia ocupacional, 3. Desempenho ocupacional, 4. Saúde da mulher. 
Dedicatória

Dedico esse trabalho aos familiares e amigos, com destaque a minha mãe que me ajudou durante o desenvolvimento da pesquisa, às mulheres que participaram do estudo e ao meu professor, Omero. 


\section{Agradecimentos}

Aos meus pais, Maria Albina e José Eduardo, meus maiores incentivadores em toda minha trajetória, que acompanharam minhas dificuldades e me ajudaram a continuar.

A minha irmã e cunhado, Jaqueline e Lucas, que participaram de todas minhas conquistas.

Aos meus avós, Olinda, Armando, Daisy e José, apesar de alguns não estarem presente, sempre estarão em meu coração.

Aos amigos que fiz ao longo de minha pesquisa, me ajudando e incentivando, Carolina, Kaliı, Ivair, Ana, Emanuela, Patrícia, Aline, Bruna, Mariana, Joice, Beatriz, Ana Paula, Arthur, Andreia e Suelen.

\section{Aos meus professores, Omero Benedicto Poli-Neto e Thaura Sofia Eiras de} Carvalho, sem a ajuda de vocês nada disso seria possível.

Agradeço à Fundação de Amparo à Pesquisa do Estado de São Paulo (Fapesp) pelo financiamento e pela confiança depositada em mim e em meu orientador para realizarmos o presente estudo.

Aos funcionários do departamento de Ginecologia e Obstetrícia e do Ambulatório de Dor pélvica crônica, que participaram diretamente e indiretamente. 


\section{Epígrafe}

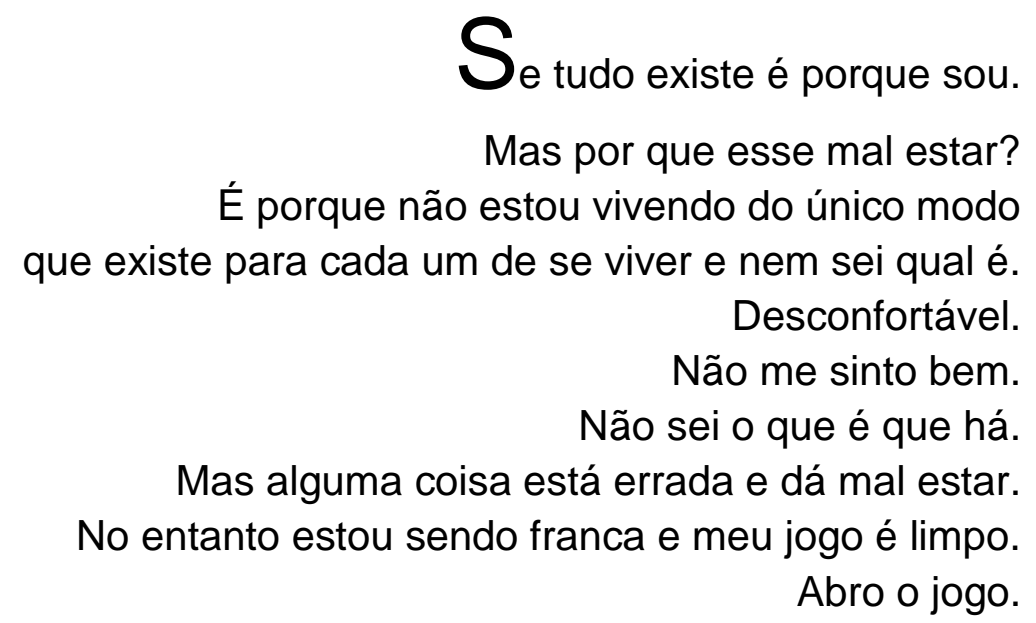

Só não conto os fatos de minha vida: sou secreta por natureza.

O que há então?

Só sei que não quero a impostura.

Recuso-me.

Eu me aprofundei, mas não acredito em mim porque meu pensamento é inventado.

(Clarice Lispector)

(Agua viva - Página 49) 


\section{Resumo}

BORTOLIEIRO, R. V. 2015. Caracterização do desempenho ocupacional de mulheres portadoras de dor pélvica crônica. Dissertação de mestrado apresentada à Faculdade de Medicina de Ribeirão Preto da Universidade de São Paulo/USP - Área de Concentração: Ginecologia e Obstetrícia, opção Biologia da Reprodução. 75f. Dissertação (Mestrado) - Programa de PósGraduação em Ginecologia e Obstetrícia, Faculdade de Medicina de Ribeirão Preto, Universidade de São Paulo, Ribeirão Preto, 2015.

Introdução: A dor crônica pélvica É uma das doenças mais frequentes entre mulheres na idade reprodutiva, e como a maioria delas, tem impacto direto na vida conjugal, social e profissional da mulher. O impacto da dor no desempenho ocupacional das mulheres afeta diretamente a atividade econômica domiciliar, visto que, atualmente, a mulher representa uma parte considerável da renda familiar. A terapia ocupacional pelo Modelo Canadense de Desempenho Ocupacional as dimensões holísticas do individuo nas 3 áreas de desempenho ocupacional: autocuidado, produtividade e lazer; e do ponto de vista do estudo da dor, os procedimentos da terapia ocupacional incluem a avaliação da multiplicidade de fatores físicos, psicossociais e ambientais agravados pela dor, nos diversos contextos de desempenho do indivíduo. Objetivo: Caracterizar o desempenho ocupacional de mulheres portadoras de DPC atendidas em um serviço terciário e verificar a associação entre as limitações ocupacionais com a presença de dor pélvica crônica, o grau de cinesiofobia e os sintomas psicológicos. Casuística e Métodos: Estudo transversal qualitativo descritivo. Foram coletadas 150 mulheres, sendo 75 mulheres com DPC (grupo: dor) e 75 mulheres saudáveis (grupo: saudáveis), todas as participantes receberam o termo de consentimento livre e esclarecido. O cálculo do tamanho da amostra foi realizado sobre proporções com margem de erro relativo em populações infinitas através da seguinte expressão: $n=\left(z^{2}\right.$. q) $/\left(\varepsilon^{2} \cdot p\right)$. As avaliações e escalas utilizadas foram: Visual analogue scale VAS (Escala visual analógica), Escala de faces, Questionários de saúde do paciente: PHQ-4 (Patient Health Questionnaire), SRQ (Self-reportQuestionnaire), Escala Tampa de Cinesiofobia, Medida Canadense de Desempenho Ocupacional (COPM). Os dados obtidos foram registrados em formulário próprio. Foi avaliada a distribuição normal das variáveis através do teste de D'Agostino e Pearson. Para verificar a associação entre grupos e variáveis qualitativas nós utilizamos o teste exato de Fisher, ou o Qui-quadrado quando mais pertinente. Resultado: Mulheres com DPC estão inseridas em menor número no mercado de trabalho em relação a mulheres saudáveis, e apresentam mais alterações no sono e histórico de cirurgia abdominal, além de terem pontuações acima da média nos testes PHQ-4, SRQ e Tampa, o tempo de dor (M) foi de 108 meses e o VAS (M) 74. As mulheres com DPC se preocupam menos com 0 "autocuidado", nas 3 subcategorias de "autocuidado" as mulheres com DPC ressaltam menos importância. Na categoria "produtividade" o nível de 
importância é homogêneo, mas apesar de mulheres com DPC estarem em menor número no mercado de trabalho, na subcategoria "trabalho" ambos os grupos apresentam preocupações em suas atividades de trabalho, em relação à "tarefas domésticas" mulheres com DPC se preocupam mais do que mulheres com saudáveis, e o inverso ocorre em "deveres". Na ultima categoria analisada ambos os grupos revelam o "lazer" e suas 3 subcategorias importantes de forma homogenia. $O$ desempenho e satisfação de mulheres com DPC é menos do que a média do grupo de mulheres Saudáveis. Conclusão: $O$ desempenho e a satisfação de mulheres com DPC são prejudicados devido, principalmente, a DPC. Alterações no sono e cirurgia abdominais anteriores, podem estar relacionadas diretamente com DPC. Essas mulheres apresentam um comportamento como a perda de identidade, isolamento social, coping e dor social. O questionário TAMPA sugere que mulheres com DPC apresentam medo ao realizar suas atividades. Nosso trabalho tenta preencher uma lacuna na literatura sobre o desempenho ocupacional em mulheres portadoras de dor pélvica crônica, pois pouco se sabe sobre a doença e o quanto interfere no desempenho ocupacional dessas mulheres.

Palavra-chave: dor crônica pélvica, terapia ocupacional, desempenho ocupacional e saúde da mulher. 


\section{Abstract}

BORTOLIEIRO, R. V. 2015. Characterization of occupational performance of women with chronic pelvic pain. Dissertação de mestrado apresentada à Faculdade de Medicina de Ribeirão Preto da Universidade de São Paulo/USP _ Área de Concentração: Ginecologia e Obstetrícia, opção Biologia da Reprodução. 75f. Dissertação (Mestrado) - Programa de Pós-Graduação em Ginecologia e Obstetrícia, Faculdade de Medicina de Ribeirão Preto, Universidade de São Paulo, Ribeirão Preto, 2015.

Introduction: Pelvic chronic pain is one of the most common disease among women of reproductive age, and like most of them, have a direct impact on marital life, social and professional woman. The impact of pain on work performance of women directly affects household economic activity, since, currently, the woman is a substantial part of household income. Occupational therapy by the Canadian Model of Occupational Performance holistic dimensions of the individual in the three areas of occupational performance: self-care, productivity and leisure; and from the viewpoint of the pain study, occupational therapy procedures include the evaluation of the multitude of physical, environmental and psychosocial factors aggravated by pain in many contexts individual's performance. Objective: To characterize the occupational performance of women with DPC met in a tertiary center and the association between occupational limitations with the presence of chronic pelvic pain, the degree of kinesiophobia and psychological symptoms. Methods: Qualitative descriptive cross-sectional study. 150 women were collected, of which 75 women with CPP (group: pain) and 75 healthy women (group: healthy), all participants were given free and informed consent form. The calculation of sample size was performed on proportions with margin of error relative in infinite populations by the following expression: $n=(z 2 \cdot q) /(\varepsilon 2 \cdot p)$. Reviews and scales used were: Visual analogue scale VAS (visual analogue scale), Face Scale, Health Questionnaires patient: PHQ-4 (Patient Health Questionnaire), SRQ (Self-report Questionnaire), Scale Tampa kinesiophobia, Measurement Canada Occupational Performance (COPM). Data were recorded on a specific form. The normal distribution was evaluated variables by D'Agostino and Pearson test. To investigate the association between groups and qualitative variables we used Fisher's exact test or chi-square when more relevant. Result: Women with DPC are inserted into fewer in the labor market compared to healthy women, and have more sleep disturbances and history of abdominal surgery, and have above average scores on the PHQ-4 tests, SRQ and Tampa, time of pain (M) was 108 months and the VAS (M) 74. Women with DPC care less about the "self-care" in the three subcategories of "self-care" women with DPC emphasize less important. In the category "productivity" the level of importance is homogeneous, but despite women with CPP are outnumbered in the labor market, in the subcategory "work" both groups have concerns about their work activities, regarding the "housekeeping" women with CPP are more concerned than women with healthy and the opposite occurs in "duties". In the last category analyzed both groups reveal the "leisure" and its 
three major subcategories of homogeneous manner. The performance and satisfaction of women with CPP is less than the average of the group Healthy women. Conclusion: The performance and satisfaction of women with CPP are harmed due mainly to DPC. Changes in previous abdominal surgery and sleep, can be directly related to DPC. These women exhibit behavior such as loss of identity, social isolation, coping and social pain. The CAP survey suggests that women with CPP have fear when performing their activities. Our work tries to fill a gap in the literature on occupational performance in women with chronic pelvic pain, because little is known about the disease and how much interferes with the work performance of those women.

Key words: chronic pelvic pain, occupational therapy, occupational performance and women's health. 


\section{Sumário}

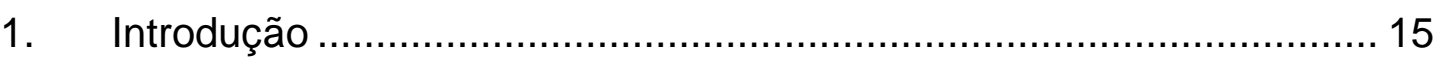

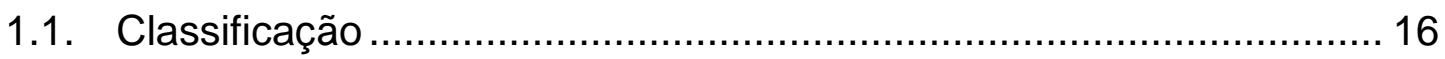

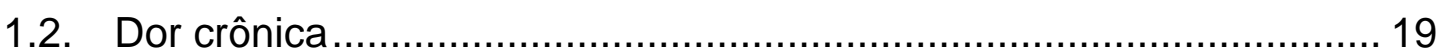

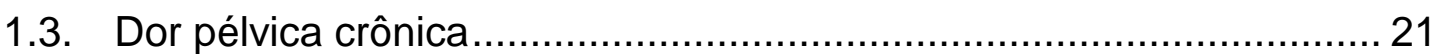

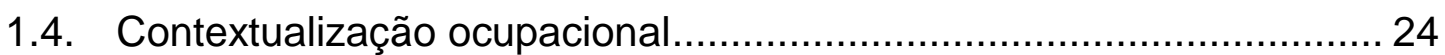

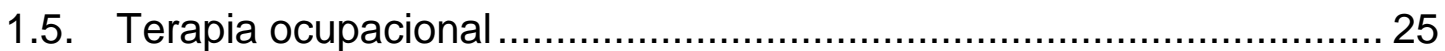

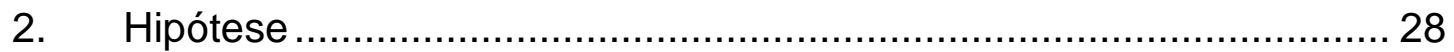

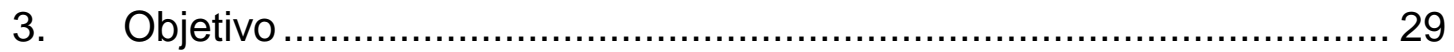

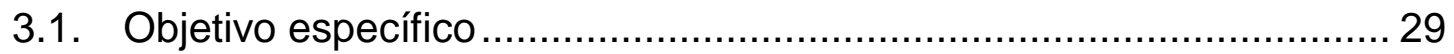

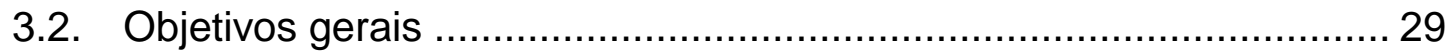

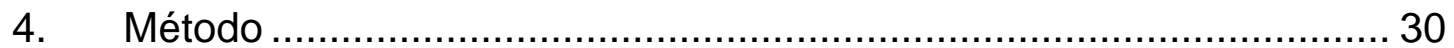

4.1. Representatividade da amostra ................................................. 30

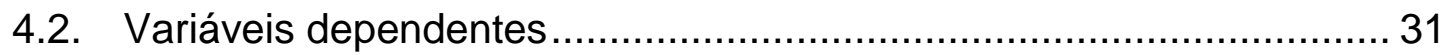

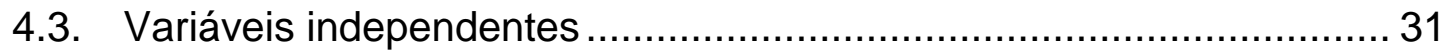

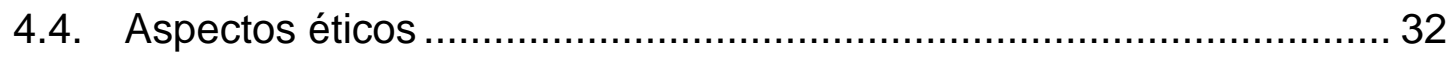

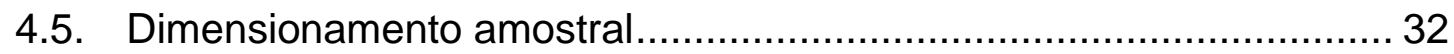

4.6. Instrumentos de mensuração ..................................................... 33

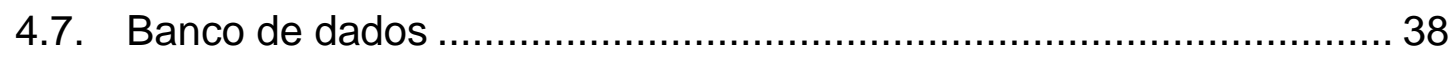

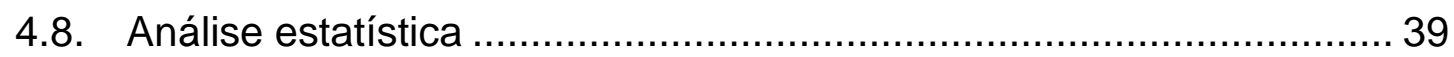




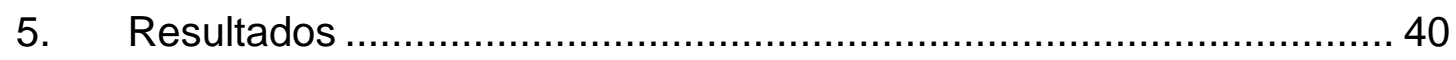

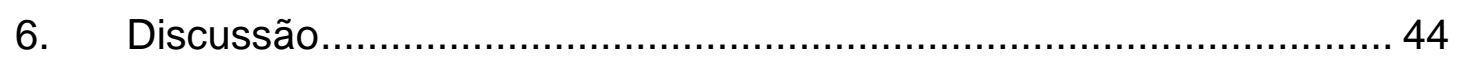

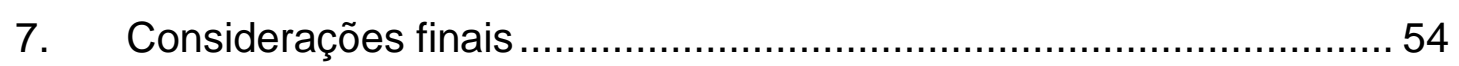

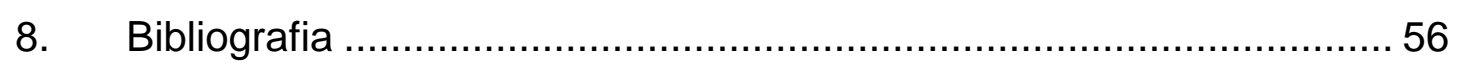

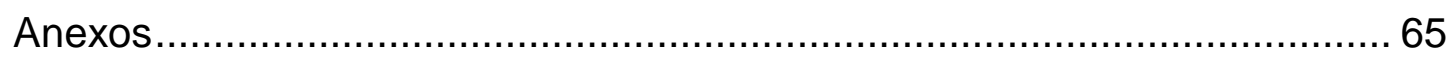

Anexo 1. Escala Visual Analógica - EVA e Escala de Faces....................... 65

Anexo 2. Patient Health Questionnaire (PHQ-4) ...................................... 66

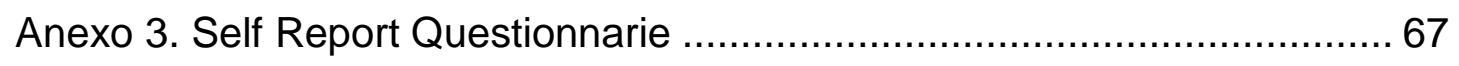

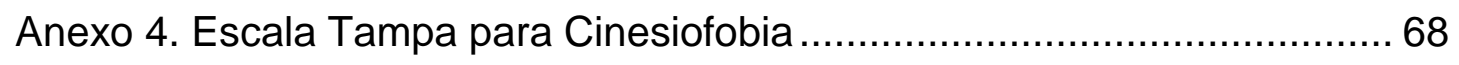

Anexo 5. Medida Canadense de Desempenho Ocupacional (COPM) ......... 69

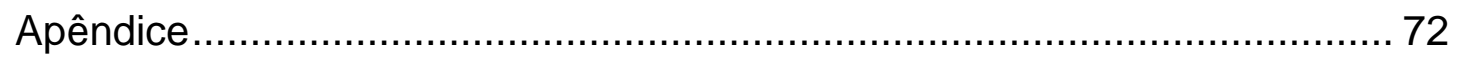

Apêndice 1. Termo de consentimento livre e esclarecido............................ 72

Apêndice 2. Carta de aprovação do CEP …………................................. 75

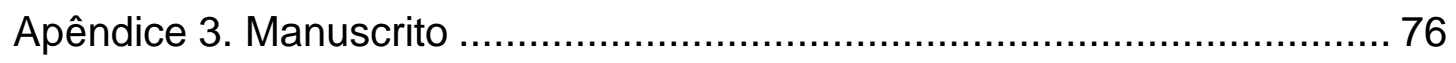




\section{Lista de tabelas}

Tabela 1 Caracterização geral da casuística 40

Tabela 2 Caracterização clínica da casuística 41

Tabela 3 Tarefas/atividades aventadas pelos sujeitos incluídos no 42 estudo conforme as categorias e subcategorias do instrumento COPM

Tabela 4 Resultado da avaliação COPM por categoria 
Lista de Fluxogramas

$\begin{array}{ll}\text { Fluxograma } 1 & 31\end{array}$

$\begin{array}{ll}\text { Fluxograma } 2 & 36\end{array}$

$\begin{array}{ll}\text { Fluxograma } 3 & 37\end{array}$ 


\section{Introdução}

A dor é um evento fisiológico importante e pode ser considerado um sinal vital, ou ainda, um sinal de alerta de agressão ao corpo, em diversas esferas (Sousa, 2002; Bottega e Fontana, 2010). É uma experiência sensorial e emocional desagradável associada a uma lesão real ou potencial, ou descrita em termos de tal, ou seja, é subjetiva e cada indivíduo aprende o uso do termo através de suas experiências no início da vida, como consequência gera uma sensação emocional. Muitos ainda consideram a dor como um sintoma, porém ela é multidimensional, apresenta-se em vários tipos e em diferentes dimensões, ela está sempre presente na vida do indivíduo, e às vezes em momentos inoportunos, afetando aspectos físicos ou a dimensão espiritual do individuo; essa questão multidimensional faz que a dor seja um problema sério e de difícil resolução, necessitando de profissionais preparados para essa gama de modalidades. É um sintoma que acompanha quase todos os processos de deterioração da saúde e, quando persistente, envolve globalmente o bem-estar, afeta a qualidade do sono, as interações sociais, as reações emocionais, a disposição e habilidades físicas. Além disso, interfere diretamente no cotidiano, inibe e altera a expressão corporal e suas relações intra e interindividuais, afasta lentamente o individuo de seu fazer habitual, modificando o autocuidado, o trabalho e lazer (Merskey e Bogduk, 2011).

Segundo a Organização Mundial da Saúde, na América do Sul considera-se que $31 \%$ da população seja acometida ou sofre por algum tipo de dor (Gureje et al., 1998). No Brasil, a informação é escassa. Pesquisa realizada em 2008, 
em Salvador - BA avaliou 2.297 indivíduos, e a prevalência de dor persistente foi de $41,4 \%$, sendo as mulheres mais afetadas, $48,4 \%$ contra $32,8 \%$ dos homens (Sá et al., 2008).Estima-se que 7 a 40\% da população mundial sofrem com algum tipo de dor persistente (Crombie et al., 1999; Dellaroza, Pimenta e Matsuo, 2007). Além do transtorno individual, a dor afeta economicamente os países. Nos EUA 40 milhões de indivíduos procuram profissionais da saúde para tratamento de dores crônicas por ano, gastando cerca de $\$ 13$ bilhões de dólares com cefaleias recorrentes, artrite e lombalgia (Siqueira, 2014). No relatório, divulgado pelo Institute of Medicine, nos EUA, a perda produtiva devido a dores recorrentes e/ou persistente, em 2010, foi $\$ 297.400$ a 335.00 milhões de dólares por ano (Steglitz, Buscemi e Ferguson, 2012). Quando observamos o que a dor acarreta, concluímos que é uma questão de saúde pública (Nunes, 2007).

Para fins de compreensão e entendimento, iremos descrever a classificação e fisiologia.

\subsection{Classificação}

Existem várias maneiras de classificar a dor. Uma das mais simples e intuitiva é a classificação por localização e duração.

Quanto à localização encontramos: dor somática, dor visceral, dor neuropática, dor psicogênica (condição considerada menos comum, não devendo ser confundida com simulações ou invenções) (Speciali e Gonçalves, 2008) ou dor referida (Guyton e Hall, 2002). As dores somáticas e viscerais podem ser enquadradas dentre as dores inflamatória e neuropática; a dor inflamatória ou 
nociceptiva é definida como dor relacionada à lesão ou ameaça de lesão de tecido não neuronal ativando nociceptores, e a dor neuropática é definida como dor devido lesão ou disfunção do sistema nervoso, resultando uma ativação anormal das vias nociceptivas (Merskey e Bogduk, 1994).

A dor somática é a sensação dolorosa, exacerbada ao movimento. É aliviada pelo repouso, bem localizada e variável, conforme a lesão; resulta da ativação e sensibilização das unidades nociceptivas periféricas e centrais (Merskey e Bogduk, 1994).

A dor visceral, segundo a Sociedade brasileira para o estudo da dor (SBED), é a dor percebida nos órgãos internos do corpo (Sbed - Sociedade Brasileira Para O Estudo Da Dor); pela Associação portuguesa para o estudo da dor (APED) tem definição como dor de origem nos órgãos internos, mal localizada, referida, sem uma associação coerente com a patologia e com forte resposta autonômica desencadeada por estímulos mínimos, deve-se a inflamação, infecção, perturbações da mobilidade dos órgãos, neoplasias, alterações nos nervos transmissores das sensações viscerais ou isquemia (Guyton e Hall, 2002).

A dor neuropática é definida pela IASP (International association for the study of pain) como uma dor iniciada ou causada por uma lesão primária ou disfunção do sistema nervoso, ou seja, uma lesão ou doença do sistema nervoso somatossensorial que acomete uma perturbação em um ou vários nervos, além disso, ela pode ser classificada como central ou periférica, dependendo assim da localização que o nervo foi acometido (Loeser e Treede, 2008). 
A dor referida apresenta sintoma percebido pelo indivíduo em uma parte do corpo que fica consideravelmente distante do tecido que primariamente gera o estímulo aferente. A dor, usualmente, é iniciada em um dos órgãos viscerais e referida na área de superfície do corpo. A dor pode ser referida em uma área do corpo que não seja exatamente coincidente com a segmentação medular correspondente à víscera que produz a dor. O conhecimento dos diferentes tipos de dor referida é importante no diagnostico clínico, porque muitos distúrbios viscerais não causam outros sinais clínicos além da dor referida (Guyton e Hall, 2002)

O segundo tipo de classificação é em relação à duração da dor, podemos descrevê-la em dois grupos (1) "dor aguda"; e (2) "dor crônica"(Loeser e Treede, 2008).

A dor aguda é usualmente causada por danos nos tecidos, que podem ter sido causados por uma infecção, lesão, ou a progressão de uma disfunção metabólica ou uma condição degenerativa; ela tende a melhorar à medida que os tecidos são reparados e respondem bem aos analgésicos e outros tratamentos da dor. Está associada a mudanças temporárias e reversíveis em alguns sistemas fisiológicos do organismo como resposta ao estresse, que consiste em aumento da pressão arterial e frequência cardíaca, resistência vascular sistêmica, entre outros. Os estímulos que causam esse tipo de dor liberam uma grande quantidade de substâncias nociceptiva, por exemplo, histamina, a bradicinina, serotonina e substância $P$, que ativam terminações neuronais periféricas (nociceptores) e conduzindo o sinal até o neurônio primário no corno dorsal da medula, o primeiro faz contato sináptico com o neurônio secundário de projeção, formando o trato espinotalâmico e 
espinorreticular, esses cruzam a medula e enviam o sinal para projeções aferentes para os centros superiores, grande parte desses aferentes fazem uma segunda sinapse no núcleo lateral e medial do tálamo, que posteriormente fazem contato sináptico com neurônios terciários (Marchand, 2008; Merskey e Bogduk, 2011).

A dor crônica (ou persistente)é uma condição de dor que normalmente se atribui o diagnóstico baseando-se num critério temporal arbitrário. Entretanto, dor crônica ou persistente, por si só, associa-se a fenômenos únicos como sensibilização central, além de mudanças fenotípicas, genotípicas e epigenéticas. Além disso, está associada à destruição tecidual, mas em geral desproporcional ao sintoma, para mais ou para menos e pode levar a um sofrimento prolongado insuportável, além disso, pode ocorrer tanto na pele como em qualquer tecido ou órgão profundo (Guyton e Hall, 2002)

O IASP define dor crônica como dor contínua ou periódica, após cicatrização da lesão; podendo ser inferior a um mês, ou mais do que seis meses (http://www.iasp-

pain.org/files/Content/ContentFolders/Publications2/FreeBooks/Classificationof-Chronic-Pain.pdf, acessado em 14 de agosto de 2015).

\subsection{Dor crônica}

Estima-se que a dor crônica acomete 1 em 5 adultos no Brasil, similar à prevalência no Canadá (Moulin et al., 2002; Siqueira, 2014; The Canadian Pain Society, 2014).O acometimento da dor crônica aumenta com a idade; no Canadá atinge cerca de $65 \%$ da população de jovens idosos e $80 \%$ 
idosos(Hadjistavropoulos et al., 2009; The Canadian Pain Society, 2014)atingindo mais mulheres e aqueles que exercem trabalhos muito intensos ou tem um nível educacional baixo (Siqueira, 2014).

Os indivíduos com dores crônicas apresentam inatividade e isolamento social, sintomas associados à depressão (Fishbain, 1999) fadiga, ansiedade, medo, amargura, frustrações, alterações no sono, e a uma redução da resistência física (American Psychiatric Association, 2002; Teixeira, 2006; Warren, Morozov e Howard, 2011; Siqueira, 2014), funcionalidade no trabalho, qualidade de vida, dificuldade para caminhar, em ter relações sexuais (Merskey e Bogduk, 1994; Teixeira, 2006; Siqueira, 2014), problemas nutricionais, dependência de medicamentos, de profissionais da saúde, de cuidadores e instituições (Siqueira, 2014) e, em casos mais graves, pode resultar até mesmo em suicídio (Fishbain, 1999).

Indivíduos com dor crônica, como cefaleia, dor facial, lombalgia, dores torácicas, abdominais, pélvicas e nas extremidades, apresentam, normalmente, comorbidades psiquiátricas, sendo que de $30 \%$ a $45 \%$ preenchem os critérios de depressão (Von Knorring et al., 1982; Teng, Humes e Demetrio, 2005). Além disso, pacientes com depressão queixam-se da dor crônica, muitas vezes, em vários segmentos do corpo sem nenhuma justificativa ou lesão, e desta forma passam por vários profissionais da saúde sem obter um diagnostico ou melhora de sua queixa (Magni et al., 1990).

As principais dores crônicas que vem sendo estudadas atualmente são: lombalgias, fibromialgia, artrite reumatoide, cefaleias, dor no pescoço, abdominal e temporamamdibular (Gureje et al., 1998; Elliott et al., 1999; Breivik 
et al., 2006). A dor pélvica crônica, apesar de ser uma doença que afeta muitas mulheres, ainda não é muito conhecida, poucos estudos são realizados e apresenta um difícil diagnóstico (Deus et al., 2014).

\subsection{Dor pélvica crônica}

A IASP define DPC como: dor crônica ou persistente percebida em estruturas relacionadas à pelve (sistema digestório, urinário, genital, miofascial ou neurológico), frequentemente associada com consequências emocionais, sexuais, comportamentais e cognitivas negativas, assim como com sintomas sugestivos de disfunções daqueles sistemas. Incluem-se tanto dor cíclica, como dismenorreia, quanto acíclica. Do ponto de vista temporal, considera-se crônica a duração igual ou superior a seis meses No entanto, seis meses é um período de tempo arbitrário, e foi escolhido pois três meses não parecem longo o bastante se incluirmos condições de dor cíclica. Assim, se a dor não for tipicamente aguda e mecanismos de sensibilização central estiverem bem documentados (hiperalgesia, principalmente), ela pode ser considerada crônica, independente do tempo dos sintomas. É importante salientar ainda que ela pode estar associada a doenças clássicas bem definidas (dor pélvica associada à doença específica) ou a nenhuma patologia óbvia (síndrome da dor pélvica crônica), o que não torna a condição ilegítima (http://www.iasppain.org/files/Content/ContentFolders/Publications2/ClassificationofChronicPain (Part II-F.pdf; acessado em 13 de novembro de 2014).

É uma das doenças mais frequentes entre mulheres na idade reprodutiva, e como a maioria delas, tem impacto direto na vida conjugal, social e profissional 
da mulher (Romao et al., 2011). Possui difícil controle, porque frequentemente não se identifica a causa primária. Via de regra, é uma condição de difícil compreensão, cuja etiologia não é clara e, usualmente, resulta de uma complexa interação entre os sistemas gastrintestinal, urinário, ginecológico, musculoesquelético, neurológico, psicológico e endócrino, influenciada ainda por fatores socioculturais (Howard, 2003; Deus et al., 2014).

Existem algumas doenças que podem estar associadas a dor pélvica crônica, dentro dos sistemas já citados, que são: síndrome do intestino irritável, constipação, carcinoma do cólon, cistite intersticial, cistite/uretrite aguda recorrente, neoplasia vesical, endometriose, doença inflamatóriapélvica, massas pélvicas e anexiais, aderências, pólipos, miomas, síndromes miofaciais, neuralgias, espasmo da musculatura do assoalho pélvico, inadequação postural, fibromialgia (Cheong e William Stones, 2006; Nogueira, Reis e Poli Neto, 2006). Há um impacto direto na sua vida conjugal, social e profissional, transformando a DPC em um sério problema de saúde pública (Romao et al., 2011).

Alguns estudos têm tentado identificar fatores de risco para a DPC, mas os resultados não são conclusivos. Há evidências que fatores como abuso de drogas ou álcool, abortos, fluxo menstrual aumentado, doença inflamatória pélvica, cesáreas, patologias pélvicas e comorbidades psicológicas (transtornos de humor, somatização, hipocondria, dentre outros) estejam associadas com um aumento do risco para a doença (Latthe et al., 2006; Deus et al., 2014). Em estudo recente realizado pelo grupo de pesquisa do AGDP ${ }^{1}$

1 - Ambulatório de ginecologia de dor pélvica. Ambulatório do Hospital das Clínicas de Ribeirão Preto (HCRP) vinculado a Universidade de São Paulo. 
identificamos como fatores independentemente associados à DPC na população de Ribeirão Preto: dispareunia, cirurgia abdominal prévia, depressão, dismenorreia, ansiedade, atividade sexual atual, dor lombar, constipação, sintomas urinários irritativos e baixo nível educacional (Silva et al., 2011).

A prevalência estimada de DPC é de $3,8 \%$ em mulheres, varia de $4 \%$ a $24 \%$ em mulheres na idade reprodutiva (Grace e Zondervan, 2004; Latthe et al., 2006; Silva et al., 2011), prevalência superior à da enxaqueca, asma e lombalgia. Não sabemos sua real prevalência em países em desenvolvimento, como o Brasil, mas em pesquisas do AGDP a prevalência estimada é de 11,5\% (Silva et al., 2011). Acredita-se que a prevalência desses países esteja próximo a de países desenvolvidos (Blyth et al., 2003), nos EUA a prevalência de DPC é de 14,7\% (Mathias et al., 1996), Reino Unido 24\% (Zondervan et al., 2001), Nova Zelândia 25,4\% (Grace e Zondervan, 2004) e Austrália 21,5\% (Pitts et al., 2008).

Cerca de $60 \%$ das mulheres com a doença nunca receberam o diagnóstico específico e $20 \%$ nunca realizaram qualquer investigação para elucidar a causa da dor. Em unidades de cuidados primários, 39\% das mulheres queixam-se de dor pélvica (Zondervan e Barlow, 2000); além disso, 40 a $50 \%$ das laparoscopias ginecológicas, $10 \%$ das consultas ginecológicas e, aproximadamente, $12 \%$ das histerectomias são devido à dor pélvica (Broder et al., 2000). A DPC está associada à qualidade de vida dessas pacientes, por afetar a mulher de uma forma geral, e por isso mulheres com DPC apresentam uma qualidade de vida pior do que mulheres sem DPC (Barcelos et al., 2010). 
Em estudos realizados a comparação da qualidade de vida de mulheres com DPC e sem DPC, utilizando o questionário SF-36, obtiveram os seguintes resultados: no Brasil os domínios de "dor" e "aspectos sociais" obtiveram uma pontuação menor (Barcelos et al., 2010); nos EUA o estudo realizado obteve uma pontuação baixa dos scores nos domínios "capacidade funcional”, "dor", "vitalidade", "estado geral de saúde", "aspectos sociais" e“saúde mental" apresentaram scores mais baixos (Haggerty et al., 2003).

\subsection{Contextualização ocupacional}

O impacto da dor no desempenho ocupacional das mulheres afeta diretamente a atividade econômica domiciliar, visto que, atualmente, a mulher representa uma parte considerável da renda familiar. A representatividade econômica na renda familiar das mulheres vem passando por mudanças sociais significativas, na década de 70 em mulheres de classe média/baixa, as mesmas contavam predominantemente em tornar-se uma senhora de família, na qual suas principais funções seriam a administração da casa e a preocupação em ter filhos e os cuidados destes, ou seja, seu papel social era apenas no âmbito familiar. A partir da década de 90, com o início da industrialização no país, as mulheres iniciaram sua participação no mercado de trabalho (Pena, 1981). Já se observa que mulheres, atualmente, contribuem com $50 \%$ ou mais da renda familiar e ainda mantém seus papeis antigos dentro do âmbito familiar (Fleck e Wagner, 2003). A dor nesse contexto gera uma preocupação crescente com o impacto das condições de "não-saúde" na vida cotidiana (Michaëlis, Kristiansen e Norredam, 2015), vindo interferir diretamente ao desempenho ocupacional, que é definido de acordo com a Occupacional Therapy Guidelines for Client- 
centred Pratice da Associação Canadense de Terapia Ocupacional, como a habilidade de realizar rotinas e desempenhar papéis e tarefas, com o objetivo de autocuidado, produtividade e lazer em resposta às demandas do meio externo e interno ao indivíduo (Chapparo e Ranka, 1997; Zanni, Bianchin e Marques, 2009).

\subsection{Terapia ocupacional}

A terapia ocupacional é uma profissão recente, reconhecida no Brasil em 1969 como nível superior. Por conta das diferenças culturais e de nacionalidades a profissão sofreu neste período uma "crise de identidade", mas nessa mesma época, devido à busca da definição de função no âmbito profissional, surgiu uma gama de produções cientificas, onde diferentes modelos de intervenções apareceram (De Carlo e Bartalotti, 2001).

Com base em nosso trabalho, iremos focar o Modelo Canadense de Desempenho Ocupacional, que focaliza a terapia ocupacional centrada no cliente, a qual este atua de forma ativa no processo de escolha, construção e avaliação de seu tratamento (Mângia, 2002).

A prática centrada no cliente passou por mudanças no decorrer de sua história, 3 guias sobre a concepção, processo e prática da Terapia Ocupacional foram formulados, e no fim chegou-se a 3 volumes sobre a Terapia Ocupacional centrada no cliente (Law, 1998). Sendo que o primeiro volume apresenta uma dimensão holística, em que a saúde está relacionada ao desempenho ocupacional; e define quatro componentes do desempenho: mental, físico, sócio-cultural e espiritual, essas dimensões estão integradas nas 3 áreas de 
desempenho ocupacional: autocuidado, produtividade e lazer. Além disso, o volume ressalta que o desempenho do indivíduo está ligado diretamente com as condições ambientais, sociais, econômicas, físicas e culturais da pessoa (Townsend, Brintnell e Staisey, 1990).

Do ponto de vista do estudo da dor, os procedimentos da terapia ocupacional incluem a avaliação da multiplicidade de fatores físicos, psicossociais e ambientais agravados pela dor, nos diversos contextos de desempenho do indivíduo. As estratégias de intervenção podem incluir equipamentos adaptados, atividades produtivas e reabilitação vocacional, treinamento de resistência para a execução da atividade, reestruturação ou restabelecimento de papéis, de hábitos e habilidades na vida diária, grupos educativos para controle da dor e para acompanhamento familiar se necessário (Strong et al., 2002). Além disso, a teoria cognitiva comportamental que surgiu a partir de 1956 (Beck e Alford, 2000) - crê que o indivíduo aprende a enfrentar, controlar e reduzir a dor empregando estratégias de coping, ou enfrentamento, e de autogerenciamento do cotidiano sob novas bases de sua relação corporal com o mundo (Nunes, 2007) - é, atualmente, a mais adotada pelos terapeutas; e as técnicas de intervenções estabelecimento de metas, relaxamento e pacing (estratégia de participação ativa), também são as mais citadas (Van Huet, Innes e Stancliffe, 2013).

Programas de treinamento ocupacional têm se mostrado eficazes na orientação/reabilitação de pacientes portadores de dor crônica desde a época de 80 (Nunes, 2007; De Carlo, Elui e Packer, 2008). Eles têm melhorado a aderência aos tratamentos médicos, à promoção de um melhor nível de desempenho funcional/ocupacional, o controle, redução, e até mesmo 
eliminação da dor pela realização de atividades e do uso de técnicas diversas, como as cognitivo-comportamentais (Nunes, 2007).

Não há até 0 momento nenhum estudo verificando sistematicamente 0 desempenho ocupacional de mulheres portadoras de dor pélvica crônica, inclusive na nossa população. Ainda, tendo em vista a distribuição de atividades profissionais desenvolvidas pelas mulheres da nossa comunidade (Silva et al., 2011), é provável que a cinesiofobia (Romao et al., 2011), ou seja, o medo de executar certos movimentos ou atividades possa interferir diretamente no desempenho ocupacional, além de limitar a reabilitação multidisciplinar e reintegração no mercado de trabalho (Lüning Bergsten et al., 2012). 


\section{Hipótese}

Mulheres portadoras de DPC podem apresentar limitações ocupacionais significativas que provavelmente interferem na sua percepção de satisfação e desempenho. Ainda, é possível que o quadro de cinesiofobia apresentada por elas possa estar associado àquelas limitações e dificultar o processo de reabilitação multidisciplinar. 


\section{Objetivo}

\subsection{Objetivo específico}

Caracterizar o desempenho ocupacional de mulheres portadoras de DPC atendidas em um serviço terciário.

\subsection{Objetivos gerais}

Verificar a associação entre as limitações ocupacionais com a presença de dor pélvica crônica, o grau de cinesiofobia e os sintomas psicológicos. 


\section{Método}

\subsection{Representatividade da amostra}

Estudo transversal qualitativo descritivo, no qual foram recrutadas mulheres com diagnóstico de DPC atendidas no ambulatório especializado (ambulatório de Ginecologia de dor pélvica - AGDP) do Hospital das clínicas da Faculdade de medicina de Ribeirão Preto vinculado a Universidade de São Paulo (HCFMRP-USP). O hospital é uma instituição pública, universitária, de atendimento terciário, referência para a região de Ribeirão Preto, contém atendimentos em diferentes áreas e especialidades, sendo uma delas o atendimento na área de Ginecologia e Obstetrícia, com diferentes ambulatórios, incluindo o AGDP, onde foi realizado o estudo.

O ambulatório recebe encaminhamentos de pacientes para abertura de casos novos e posteriormente seguir o tratamento. Em nosso estudo foram abordadas pacientes que ainda não realizavam o tratamento e foram encaminhadas para abertura de casos novos ${ }^{2}$, compondo o grupo "dor". Para o critério de inclusão as pacientes deveriam ter idade superior a 18 anos ou não estarem na menopausa, foi coletado 75 mulheres. O fluxograma 1 nos esclarece como foi feita a seleção dos indivíduos.

As participantes do grupo controle (grupo "saudáveis") foram recrutadas no próprio HCFMRP, porém foram abordados indivíduos que se apresentavam como acompanhante do paciente ou que trabalhasse no hospital, desde que

\footnotetext{
${ }^{2}$ Etapa inicial do ambulatório de ginecologia em dor pélvica (AGDP) - HCFMRP/USP para iniciar o tratamento.
} 
não apresentassem algum tipo de doença ou condição de enfermidade e idade entre 18 anos ou até a menopausa, foi coletado 75 mulheres.

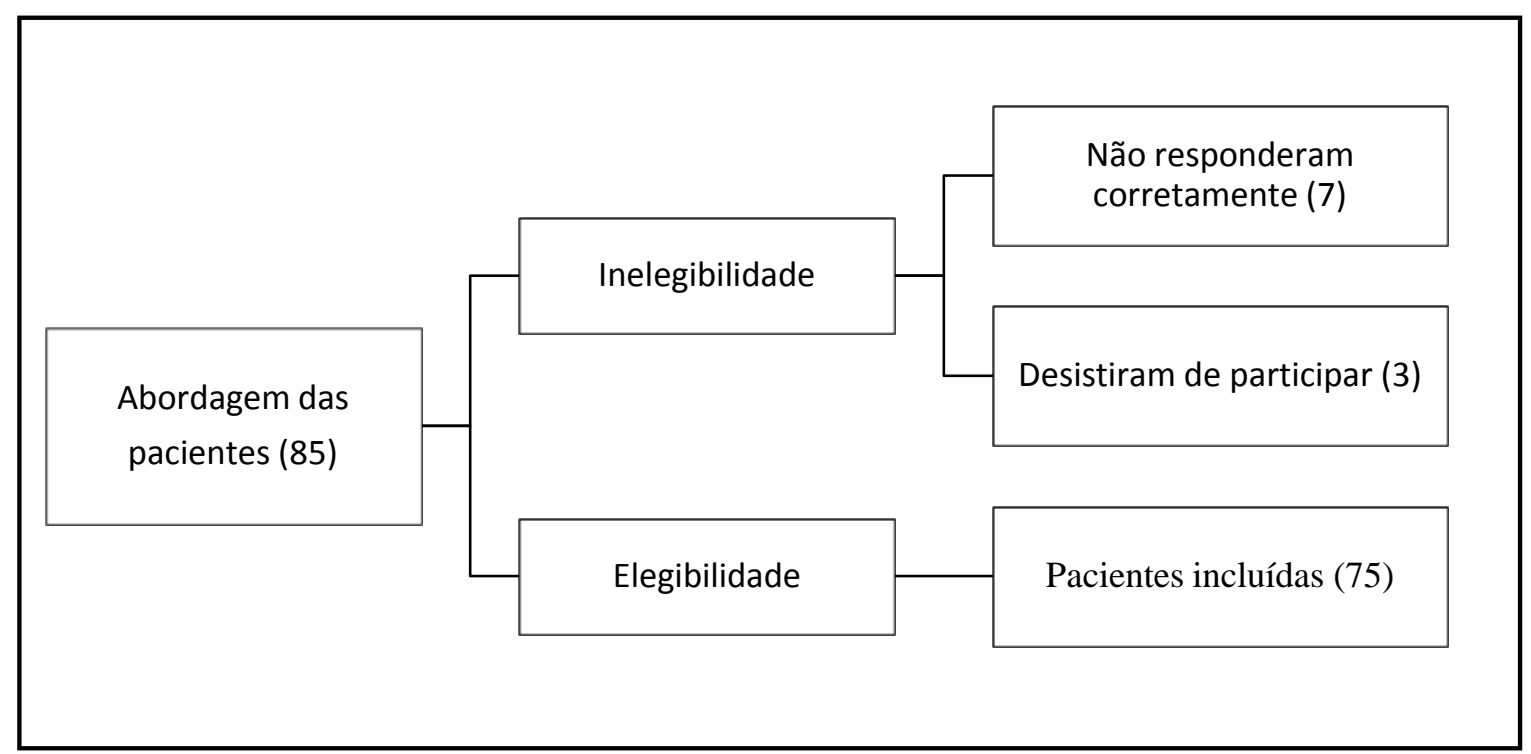

Fluxograma 2

\subsection{Variáveis dependentes}

Satisfação e desempenho ocupacional; cinesiofobia; sintomas psicológicos.

\subsection{Variáveis independentes}

Relacionamento conjugal, alterações de sono, escolaridade, atividade profissional, religião, cirurgias abdominais, menarca, paridade, obesidade, constipação intestinal, raça, escores de saúde, nível de instrução. 


\subsection{Aspectos éticos}

Todas as participantes receberam esclarecimentos individuais a respeito dos objetivos, relevância e metodologia do estudo por meio de exposição oral e escrita pelo termo de consentimento livre e esclarecido que encontra-se no apêndice 1. Os princípios de confiabilidade dos dados obtidos, manutenção da autonomia dos participantes, sigilo à identificação pessoal e beneficência dos propósitos serão respeitados. O estudo foi iniciado apenas após aprovação pelo CEP HCFMRPUSP, número do processo 9091/2012 (Apêndice 2).

\subsection{Dimensionamento amostral}

O cálculo do tamanho da amostra foi realizado sobre proporções com margem de erro relativo em populações infinitas através da seguinte expressão: $n=\left(z^{2}\right.$. $q) /\left(\varepsilon^{2} \cdot p\right)$

Consideramos: grau de confiança $=95 \%$, portanto $z=1,96$; prevalência estimada de limitações ocupacionais $=30 \%$, portanto $p=0,30$ e $q=0,70$; e erro relativo $(\varepsilon)=30 \%$. Assim, temos que o tamanho da amostra determinada é igual a 100 mulheres em cada grupo, podendo variar de 75 a 125, para que possa ser efetuada uma estimativa da prevalência de limitação ocupacional para a população estudada, com $95 \%$ de confiança de que o erro relativo da estimativa não ultrapasse $30 \%$ da taxa de prevalência (10\% para mais ou para menos), considerando uma prevalência real máxima de 30\%. Uma análise de poder do teste será realizada a cada inclusão de 25 sujeitos, visto que não os 
dados utilizados para o cálculo amostral são derivados de estudos que não avaliaram mulheres com DPC (Andrew Walsh et al., 2004; Persson, RivanoFischer e Eklund, 2004; Nickel et al., 2012).

\subsection{Instrumentos de mensuração}

1. Visual analogue scale VAS (Escala visual analógica) (Pesudovs, Craigie e Roberton, 2005) e Escala de faces (Anexo 1): A escala ininterrupta de 100 milímetros na qual a paciente é orientada a marcar o ponto que corresponde à dor referida, lembrando que o início da escala $(0)$ corresponde à ausência de dor e o término da escala (10) corresponde à pior dor já vivenciada (parto sem analgesia, infarto do miocárdio, dor de dente, litíase urinária) ou imaginada; juntamente a paciente escolhe entre cinco opções a figura que melhor representa sua autoimagem com relação dor que ela está presenciando;

2. Questionários de saúde do paciente: PHQ-4 (Patient Health Questionnaire) (De Lima Osório et al., 2009; Kroenke et al., 2009); SRQ (Self-report Questionnaire)(Harding et al., 1980; Mari e Williams, 1986):

O Patient Health Questionnaire (PHQ-4) foi desenvolvido para auxiliar na triagem, em ambulatórios ou visitas domiciliares, para depressão e ansiedade. Pode ser administrado por profissionais de saúde ou auto administrado (Anexo 2). É um questionário de 4 itens, com pontuação de $0 \mathrm{a}$ 3 pontos em cada item; os scores podem ser considerados como normal (02 pontos), leve (3-5 pontos), moderada (6-8 pontos) e grave (9-12 pontos). Para critério de análise, consideramos como variável quantitativa e como 
variável qualitativa (se maior ou igual a 5 consideramos presença de sintomas significativos) (De Lima Osório et al., 2009; Kroenke et al., 2009).

O Self-reportQuestionnaire (SRQ) foi desenvolvido, pela OMS, para sugerir possíveis sintomas de transtornos mentais; o instrumento não descreve nenhum diagnóstico específico (Mari e Williams, 1986). O SRQ inclui 24 questões, sendo divididos em A e B, o primeiro contem 20 questões para triagem de distúrbios não psicóticos e o B para detecção de distúrbios psicóticos (Anexo 3). Em nosso estudo não iremos utilizar o SRQ-B, devido investigar possíveis distúrbios psicóticos, o que não é de interessante. É um instrumento de fácil aplicabilidade ondeo próprio individuo realiza a avaliação, a forma de resposta é dicotômica (sim/não). Para critério de análise consideramos como variável quantitativa e como variável qualitativa (se maior ou igual a 8 consideramos presença de sintomas significativos)(Borges e Medrado, 1993).

3. Escala Tampa de Cinesiofobia (Roelofs et al., 2004; De Souza et al., 2008; Lamé et al., 2008): A escala Tampa é um questionário de 17 itens que tem como objetivo avaliar o medo de injúria devido ao movimento. Cada item é provido com uma escala tipo Likert de 4 pontos variando de "concordo totalmente" a "discordo totalmente", e o escore varia de 17 a 68 pontos e, quanto maior o escore, maior o medo de movimento (Anexo 4).

4. Medida Canadense de Desempenho Ocupacional (COPM) (Carswell et al., 2004): A avaliação COPM foi desenvolvida por pesquisadores canadenses, em 1990 por Law et al., com o intuito de ser utilizada como guia para terapeutas ocupacionais, baseando-se na prática centrada no cliente. $\mathrm{O}$ desenvolvimento da medida teve como aspecto estruturador o Modelo 
Canadense de Desempenho Ocupacional, focalizando o desempenho nas áreas de autocuidado, produtividade e lazer, bem como os componentes de desempenho (físico, mental, sociocultural e espiritual), o ambiente, o estágio de desenvolvimento, os papéis na vida e a motivação do sujeito com a finalidade de detectar mudanças na auto percepção do individuo ao longo do tempo (anexo 5) (Law, 2009), possibilitando o desenvolvimento de programas individualizados e detecção de mudanças no desempenho após um período de intervenção (Carswell et al., 2004).

Recentemente foi traduzido para o português e publicado no Brasil (Magalhães, Magalhães e Cardoso, 2009). O COPM é um instrumento válido com ampla aplicabilidade, embora, em alguns casos, necessite de adaptações ou reestruturação da forma de pensar no cliente(Caldas, Facundes e Silva, 2011). Em nossa pesquisa a escala foi aplicada de forma adaptativa, como um roteiro, para medirmos o quanto a DPC interfere nas ocupações e satisfações das mulheres com DPC.

A avaliação é dividida em três etapas, o fluxograma, a seguir, nos mostra como funciona (fluxograma 2). 


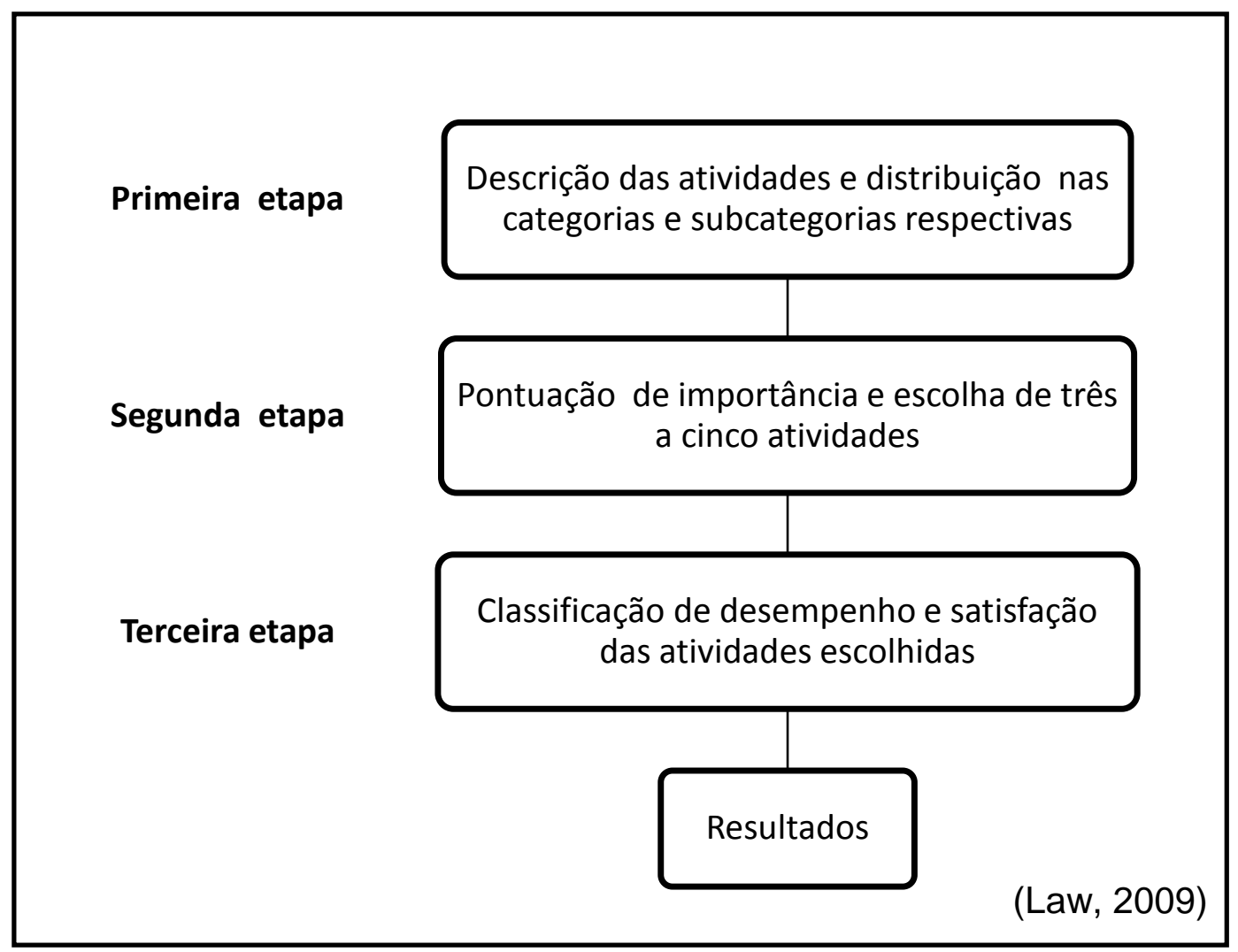

\section{Fluxograma 2}

A entrevista ocorreu em uma sala restrita, utilizando um gravador. A primeira etapa consistiu na descrição, pelo indivíduo, de suas ocupações diárias (considerando as que precisem ou que de fato realizem). As atividades são distribuídas na avaliação de acordo com suas categorias e subcategorias (fluxograma 3). As categorias e subcategorias referem-se a (Law, 2009):

- Cuidados pessoais = higiene, alimentação, vestuários e outros;

- Mobilidade = transferências, mobilidade dentro e fora de casa e outros;

- Independência fora de casa = transportes, compras, finanças e outros;

- Trabalho = procurar/ manter emprego, atividades voluntárias e outros;

- Tarefas domésticas = limpezas, lavagem de roupas, preparação de refeições e outros;

- Deveres (ou Brincar/escola) $=$ deveres além do trabalho e tarefas domésticas e outros; 
- Recreação tranquila = hobbies, leitura, artesanato, TV, computador e outros;

- Recreação ativa = esportes, passeios, viagens e outros;

- Socialização = visitas, telefonemas, festas, escrever cartas e outros.

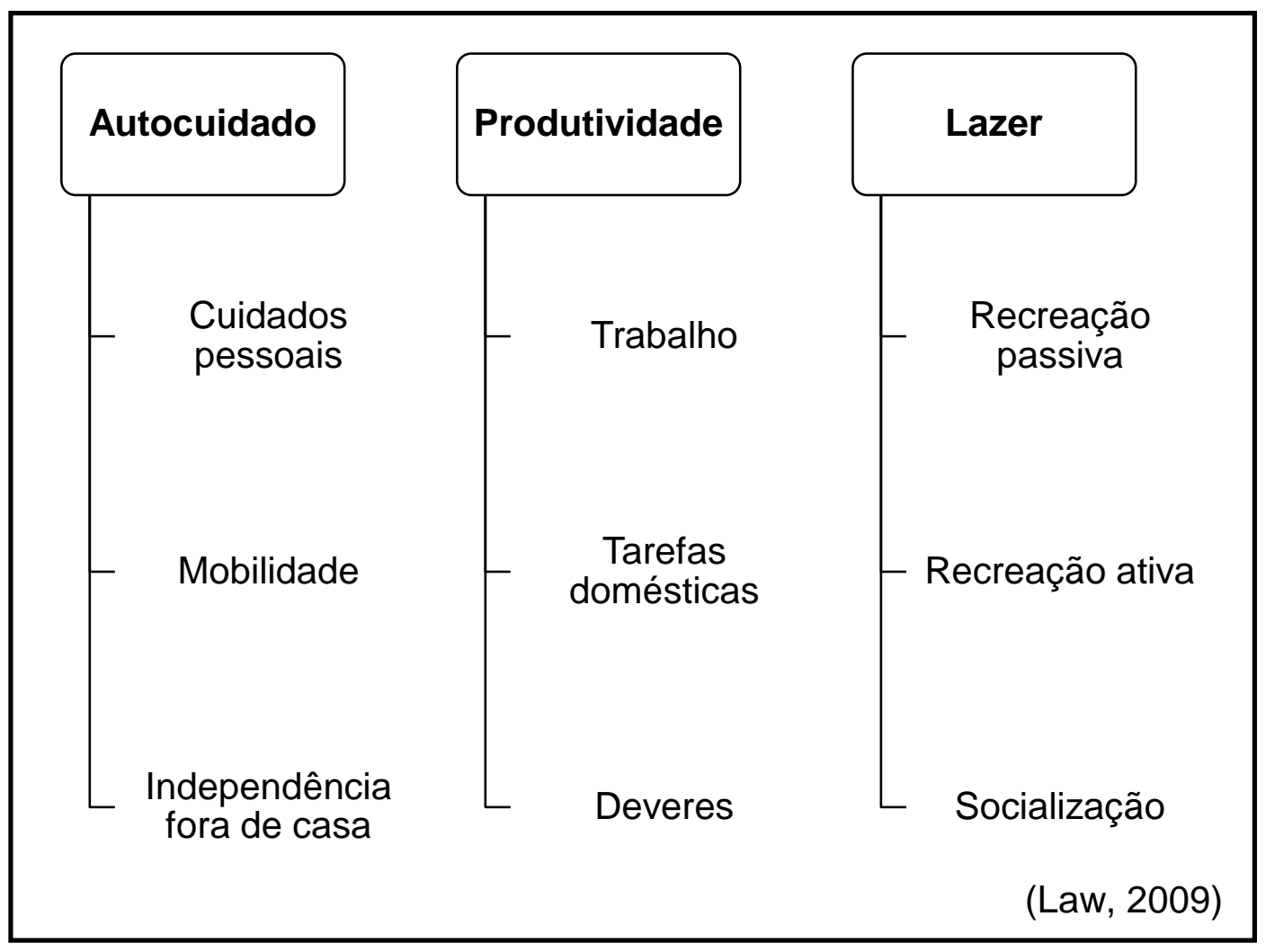

\section{Fluxograma 3}

$\mathrm{Na}$ segunda etapa foi pedido ao sujeito que pontue cada atividade em uma escala de 1 a 10 pontos, utilizando cartão específico da avaliação (Anexo 5 "escala de importância"). Após a classificação de "importância", foi pedido ao individuo que escolha de 3 a 5 atividades, que apresentam pontuações altas de importância (essa informação é necessária para orientar o cliente a escolher as atividades que, para ele, são importantes) e sejam essenciais, para prosseguir a terceira etapa. 
A terceira etapa da avaliação foi a classificação do "desempenho" e "satisfação" das atividades que foram escolhidas anteriormente pelo individuo, utilizaram-se dois cartões, um de "desempenho" e outro de "satisfação", para a classificação; cada cartão possui uma escala de 1 a 10 pontos (Anexo 5 "escala de desempenho" e "escala de satisfação"). Nessa etapa o sujeito foi questionado quanto ao seu desempenho atual na atividade e sua satisfação ao desempenho realizado; esse questionamento foi necessário para que 0 indivíduo, em sua auto avaliação, respondesse o que é de interesse.

O resultado da avaliação foi feito com a soma das pontuações, de "desempenho" e "satisfação", e dividido pelo número de atividades avaliadas; p.e.: se forem descritas três atividades: a1, a2 e a3; o resultado do "desempenho" = pontuação do desempenho a1+pontuação do desempenho a2+pontuação do desempenho a3/3; e o resultado de "satisfação" = pontuação da satisfação a1+pontuação da satisfação a2+ pontuação da satisfação a3/3. Os resultados podem variar de 1 a 10 .

Os resultados obtidos foram organizados e tabulados de forma geral. Em nosso trabalho além de obtermos um resultado geral, também temos os resultados de desempenho e satisfação por categoria (autocuidado, produtividade e lazer).

\subsection{Banco de dados}

Os dados obtidos foram registrados em formulário próprio preparado especificamente para este fim e transferidos para o banco de dados eletrônico. Foi feito backup semanal. A confecção do banco de dados e das planilhas para a análise estatística, tabelas e gráficos foram realizadas com auxílio dos 
aplicativos FileMaker Pro 11, GraphPadPrism 5.0 for Windows. Os dados de identificação pessoal serão codificados e mantidos em sigilo.

\subsection{Análise estatística}

O grupo de mulheres saudáveis está representado pelo grupo "saudáveis", enquanto que as mulheres com DPC estão representadas pelo grupo "dor".

Foi avaliada a distribuição normal das variáveis através do teste de D’Agostino e Pearson. Para verificar a associação entre grupos e variáveis qualitativas nós utilizamos o teste exato de Fisher, ou o Qui-quadrado quando mais pertinente. Para comparar as variáveis quantitativas de caracterização entre os grupos com e sem dor pélvica crônica utilizamos o teste t ou o teste de Wilcoxon, quando detectado distribuição normal ou não, respectivamente. Utilizamos um modelo de regressão múltipla ajustado (fitmode/) para verificar e estimar a relação entre as variáveis.Análise de correlação múltipla foi utilizada para verificar correlação entre satisfação e desempenho, intensidade e duração de dor, cinesiofobia, sintomas psicológicos $(P H Q>=5)$ e sintomas clínicos (PHQ>=8). Consideramos alfa igual a $5 \%$. 


\section{Resultados}

A seguir serão apresentados os resultados obtidos na pesquisa. Foram incluídas efetivamente 150 mulheres, sendo 75 em cada grupo. Não foi possível parear os grupos. A Tabela 1 apresenta a caracterização da casuística.

Tabela 1. Caracterização geral da casuística

\begin{tabular}{|c|c|c|}
\hline & Saudáveis & Dor \\
\hline Idade, média (desvio-padrão) & 31,5 & 39,6 \\
\hline$<21$ anos $(\%)$ & $3(4 \%)$ & $1(1,3 \%)$ \\
\hline $21-40$ anos (\%) & $62(82,7 \%)$ & $38(50,7 \%)$ \\
\hline$>40$ anos (\%) & $10(13,3 \%)$ & $36(48 \%)$ \\
\hline União estável & $46(61,7 \%)$ & $54(72 \%)$ \\
\hline \multicolumn{3}{|l|}{ Escolaridade } \\
\hline$<8(\%)$ & $7(10 \%)$ & $19(25,3 \%)$ \\
\hline 8 a $11(\%)$ & $10(13,3 \%)$ & $24(32,4 \%)$ \\
\hline 12 a $15(\%)$ & $20(26,7 \%)$ & $23(31,1 \%)$ \\
\hline $16+(\%)$ & $38(50 \%)$ & $9(12,2 \%)$ \\
\hline Profissão Remunerada (\%) & 80,3 & 28,4 \\
\hline \multicolumn{3}{|l|}{ Religião } \\
\hline Ateísmo (\%) & $7(10 \%)$ & $2(2,8 \%)$ \\
\hline Catolicismo (\%) & $39(51,7 \%)$ & $29(39,1 \%)$ \\
\hline Outros (\%) & $29(38,3 \%)$ & $44(58,7 \%)$ \\
\hline \multicolumn{3}{|l|}{ Cor } \\
\hline Branco (\%) & $63(85,2 \%)$ & $69(91,8 \%)$ \\
\hline Negro (\%) & $12(17,6 \%)$ & $6(8,2 \%)$ \\
\hline
\end{tabular}


A tabela dois apresenta os resultados da avaliação clínica.

Tabela 2. Caracterização clínica da casuística

\begin{tabular}{|c|c|c|c|}
\hline & Saudáveis & Dor & $p$ \\
\hline Alterações no sono (\%) & $11(16,7 \%)$ & $37(49,3 \%)$ & $<0,0001$ \\
\hline Menarca (Me) & 13 & 12 & 0,1936 \\
\hline Parto, mediana (intervalo) & $1(0-4)$ & $1(0-6)$ & 0,3211 \\
\hline Cirurgia Abdominal (\%) & $9(12,2 \%)$ & $56(75,3 \%)$ & $<0,0001$ \\
\hline Constipação (\%) & $13(18,3 \%)$ & $26(34,2 \%)$ & 0,0422 \\
\hline PHQ-4 (Me) & 2 & 5,5 & 0,0008 \\
\hline$P H Q-4 \geq 5$ & $15(25 \%)$ & $40(54,8 \%)$ & 0,0004 \\
\hline SRQ A (Me) & 4,94 & 9 & $<0,0001$ \\
\hline$S R Q \geq 8$ & $12(20 \%)$ & $40(54,8 \%)$ & $<0,0001$ \\
\hline Dismenorreia (\%) & - & $39(52 \%)$ & \\
\hline Dispareunia (\%) & - & $32(42,5 \%)$ & \\
\hline Tampa & - & 45 & \\
\hline Tempo de DPC & - & 108meses & \\
\hline VAS* & - & 74 & \\
\hline
\end{tabular}


A tabela 3 mostra as atividades que foram escolhidas como importantes pelos sujeitos para a terceira etapa da avaliação COPM.

Tabela 3. Tarefas/atividades aventadas pelos sujeitos incluídos no estudo conforme as categorias e subcategorias do instrumento COPM.

\begin{tabular}{|c|c|c|c|c|c|}
\hline & $\begin{array}{c}\text { Saudáveis } \\
n=75\end{array}$ & $(\%)$ & $\begin{array}{c}\text { Dor } \\
n=75\end{array}$ & $(\%)$ & $\mathbf{p}$ \\
\hline Autocuidado & 69 & 92,0 & 61 & 81,3 & 0.055 \\
\hline Cuidados pessoais & 65 & 86,7 & 54 & 72,0 & 0.058 \\
\hline - Higiene & 63 & 84,0 & 45 & 60,0 & \\
\hline - Alimentação & 27 & 36,0 & 19 & 25,3 & \\
\hline - Vestuário & 5 & 6,7 & 13 & 17,3 & \\
\hline - Tomar medicação & 0 & 0,00 & 1 & 1,6 & \\
\hline Mobilidade funcional & 14 & 18,7 & 9 & 12,0 & 0.00013 \\
\hline - Sentar & 0 & 0,0 & 4 & 5,3 & \\
\hline - Andar & 0 & 0,0 & 5 & 6,7 & \\
\hline - Sair de casa & 14 & 18,7 & 2 & 2,7 & \\
\hline Independência fora de casa & 9 & 12,0 & 6 & 8,0 & 0.199 \\
\hline - Transporte & 4 & 5,3 & 3 & 4,0 & \\
\hline - Compras & 5 & 6,7 & 2 & 2,7 & \\
\hline - Finanças & 0 & 0,0 & 2 & 2,7 & \\
\hline Produtividade & 68 & 90,7 & 64 & 85,3 & 0.315 \\
\hline Trabalho & 30 & 40,0 & 26 & 34,7 & 0.7297 \\
\hline Tarefas domésticas & 13 & 17,3 & 29 & 38,7 & 0.0001 \\
\hline Deveres & 58 & 77,3 & 36 & 48,0 & 0.0001 \\
\hline Lazer & 63 & 84,0 & 69 & 92,0 & 0.132 \\
\hline Recreação tranquila & 21 & 28,0 & 29 & 38,7 & 0.2252 \\
\hline Recreação ativa & 31 & 41,3 & 35 & 46,7 & 0.6219 \\
\hline Socialização & 40 & 53,3 & 44 & 58,7 & 0.6219 \\
\hline
\end{tabular}


A terceira etapa da avaliação constituiu na auto avaliação da entrevista e o resultado da avaliação (Tabela 4). Os indivíduos quantificam a forma com que desempenham suas atividades e a satisfação ao realiza-las. Por se tratar de diferentes variáveis, foi considerado, inicialmente, o nível de desempenho e satisfação de cada categoria e posteriormente calculado o desempenho e satisfação total.

Tabela 4. Resultado da avaliação COPM por categoria

\begin{tabular}{lccc}
\hline & Saudáveis & Dor & $\mathbf{p}^{*}$ \\
\hline Desempenho & & & \\
Autocuidado (M) & 9,8 & 6,3 & $<0,0001$ \\
Produtividade (M) & 9,6 & 5,4 & $<0,0001$ \\
Lazer (M) & 9,6 & 4,8 & $<0,0001$ \\
Total (M) & 9,8 & 5,4 & $<0,0001$ \\
Satisfação & & & \\
Autocuidado (M) & 9,7 & 4,7 & $<0,0001$ \\
Produtividade (M) & 9,6 & 4,2 & $<0,0001$ \\
Lazer (M) & 9,5 & 4,1 & $<0,0001$ \\
Total (M) & 9,6 & 4,4 & $<0,0001$
\end{tabular}

*Análise através do teste de Wilcoxon (Kruskal-Wallis) com aproximação normal, confirmado pela regressão múltipla (fitmodel). Foram analisadas a interferência das variáveis: presença de dor pélvica crônica, estado civil, escolaridade, profissão remunerada, religião, antecedente de cirurgia abdominal, sintomas psicológicos (considerando escore $\mathrm{PHQ}>=5$ ), sintomas gerais (considerando $S R Q>=8$ ) e idade. 


\section{Discussão}

Nosso estudo demonstra que os níveis de desempenho e satisfação em atividades julgadas importantes são menores entre mulheres portadoras de dor pélvica crônica, comparado com controles saudáveis, mesmo quando ponderado pela influência de outras covariáveis. Esse resultado vem de encontro com a literatura atual, onde estudos recentes nos mostram que indivíduos com dores crônicas apresentam uma diminuição no desempenho e satisfação de suas atividades diárias, o que se associa a maiores escores de dor (Silvemark et al., 2008; Mcnamee e Mendolia, 2014; Perneros, Tropp e Sandqvist, 2014). Além disso, indivíduos com dores crônicas que não estão inseridos no mercado de trabalho apresentam um nível de satisfação pessoal menor, do que aqueles indivíduos que também apresentam dores crônicas e estão ativos profissionalmente (Mcnamee e Mendolia, 2014).

Como podemos observar nas características da casuística, os indivíduos que apresentam dores crônicas estão embaixo número no mercado de trabalho, o que contribui, segundo os estudos apresentados, para um menor nível de satisfação. Além disso, um estudo realizado em 2015 aponta que indivíduos com dores crônicas apresentam a doença como uma causa de efeito negativo no desempenho diário de suas atividades e em seu bem-estar emocional (Strand et al., 2015).

De acordo com os dados gerais da casuística à idade de nosso grupo estudado está acima da média da literatura estudada (Barcelos et al., 2010; Deus et al., 2014). Em relação ao nível educacional podemos observar uma discrepância 
entre os grupos, mulheres saudáveis apresentam um nível educacional superior que mulheres com dor. Em estudo realizado no Brasil em 2014, a pesquisa revela que $60 \%$ das mulheres com DPC apresentam estão no nível fundamental (Deus et al., 2014).

Podemos observar que a união estável e raça em ambos os grupos são homogêneos, a religião também pode ser considerada homogenia, não em relação ao tipo de crença, mas em ambos os grupos os participantes seguem alguma tipo religião.

O grupo de mulheres com dor apresenta dependência financeira, cerca de $70 \%$ não apresentam profissão remunerada, este número é até alto de acordo com a literatura brasileira, pois quando comparamos com a pesquisa realizada em 2014, observa-se que 53\% das mulheres com DPC, que participaram da pesquisa, não possuíam trabalho remunerado (Deus et al., 2014).

Alterações no sono também foram discrepantes e podem ser consideradas como um possível fator de risco, uma vez que $50 \%$ do grupo dor apresentam uma qualidade de sono ruim; nosso resultado vem de encontro com a literatura, pois discutem que indivíduos com dores crônicas apresentam alterações no sono (American Psychiatric Association, 1994; Teixeira, 2006; Warren, Morozov e Howard, 2011; Siqueira, 2014). A idade da menarca está próxima entre os grupos e assim como na literatura (Barcelos et al., 2010; Deus et al., 2014).

Podemos observar que o número médio de partos é o mesmo em ambos os grupos; em comparação a outro estudo realizado no Brasil em 2014, nosso resultado é menor, uma vez que no estudo foi encontrado $70 \%$ das mulheres com DPC tem de 1-3 filhos (Deus et al., 2014). A cirurgia abdominal está 
presente em cerca de $70 \%$ no grupo de mulheres com dor, o que vem de encontro com a literatura estudada, que antecedentes cirúrgicos são fatores de risco para DPC (Silva et al., 2011; Deus et al., 2014).

A constipação em nossa pesquisa não parece estar ligada diretamente com o desenvolvimento de DPC, uma vez que em ambos os grupos ela está presente, mas as mulheres com DPC apresentam um número maior de constipação, o que nos sugere que pode estar ligada indiretamente a DPC.

Estudos apontam disminorreia e dispareunia como fatores de risco para DPC (Latthe et al., 2006; Deus et al., 2014), em nosso estudo, foi possível observar que estão presentes em $\pm 50 \%$ das mulheres do grupo "dor". Estudos realizados no Brasil em 2010 e 2014 apresentam que 87\% das mulheres com DPC tem dismenorreia (Barcelos et al., 2010) e 65\% das mulheres com DPC apresentavam dispareunia severa (Deus et al., 2014).

O resultado médio dos questionários de saúde mental $\mathrm{PHQ}-4$ e SRQ-A apresenta que mulheres com DPC estão acima da pontuação considerada "normal", $\geq 5$ e $\geq 8$ respectivamente, o que sugere que essas mulheres podem vir a ter um acometimento mental leve. Nosso resultado vem de acordo com a literatura estudada, indivíduos com dores crônicas apresentam muitas vezes um acometimento mental, relacionados à ansiedade, medo, amargura, frustações (American Psychiatric Association, 1994; Teixeira, 2006; Warren, Morozov e Howard, 2011; Siqueira, 2014) e comorbidades psicológicas (transtornos de humor, somatização, hipocondria, dentre outros) estejam associadas com um aumento do risco para a doença (Latthe et al., 2006; Deus et al., 2014). 
O questionário TAMPA foi utilizado para medir o medo das mulheres em realizar movimentos devido à dor. Em nosso estudo podemos observar que mulheres com DPC (45 pontos) apresentam uma alta pontuação indicando que essa população pode estar apresentando medo de realizar atividades devido à dor, o que responde nossa hipótese secundária, além de interferir desempenho e satisfação de suas atividades ocupacionais.

Em relação ao tempo de dor e a escala visual analógica; o nosso grupo apresentou uma média de dor pélvica crônica em 108 meses (9 anos), quando comparamos essa pontuação ao estudo realizado no Brasil, temos que o tempo de dor das mulheres coletadas foi entre 62,3 a 72,3 meses, tempo inferior as mulheres atendidas em nosso ambulatório (Barcelos et al., 2010); o resultado da escala de dor de 74 pontos $(0-100)$ nos revela que a média de dor dessa população é superior ao nível de dor moderado.

Em relação à avaliação COPM, nossos resultados serão discutidos a seguir e estão de acordo com as categorias e subcategorias, juntamente a alguns trechos de falas durante a entrevista.

\section{Autocuidado}

Nossos resultados sugerem que mulheres com DPC não tem tendência em se preocupar com o autocuidado, quando analisadas as subcategorias de forma independente os resultados nos indicam uma possível diferença na importância das atividades do "cuidado pessoal", principalmente em higiene pessoal, alimentação e vestuário, na literatura encontramos que mulheres com dor 
crônica apresentam dificuldades em atividades diárias, como tomar banho e se trocarem; em alguns momentos relatam necessidade de descanso, o que as impede de cumprir a atividade (Michaëlis, Kristiansen e Norredam, 2015).

“...eu acordo e vou para o banheiro e lavo o rosto né! Tem que lavar, as vezes sento no vaso para fazer xixi né, e já entro no banho, porque ajuda a melhorar a dor e volto pra cama para deitar." (Indivíduo 3 - grupo "dor")

“...a pelo menos escovar o dente e limpar o rosto tem que fazer né?” (Indivíduo 10 - grupo "dor")

Quando analisado a subcategoria "mobilidade funcional" temos uma diferença de resultados entre os grupos, onde mulheres com DPC se importam e relatam o quão importante é andar e sentar-se. Um estudo realizado em 2015, com indivíduos com dores crônicas, também faz referências às falas de mulheres com dores crônicas que sentem dificuldade em sentar ou levantar-se; o autor descreve que não é a dor que elas sentem que as incomodam, mas sim a dor que durante o movimento é intensificada (Morden, Jinks e Ong, 2015).

Eu fico o dia inteiro sentada, é péssimo, porque minha dor vem quando fico sentada e eu quero ir embora para deitar, porque parece que melhora, as vezes fico de pé, pra vê se passa" (Individuo 53 - grupo "dor")

A mesma subcategoria também ressalta que "sair de casa" não é considerado de importância para mulheres, sendo que, o artigo de Michaëlis, 2015, associa a falta de importância de mulheres com dor crônica em sair de casa com o isolamento social, muita dessas mulheres tem medo de sair de casa, devido à aparência, que já foi discutido no autocuidado, e pela dor ser imprevisível e incontrolável, acarretando em um isolamento social. 
"Eu acho importante sair de casa, eu gostava de resolver tudo, até de ir no banco, mas hoje peço pro meu filho ou pro meu marido..." (Indivíduo 35 - grupo "dor")

"Eu não gosto de sair de casa, prefiro ficar no meu canto com a dor da minha barriga” (Indivíduo 70 - grupo “dor”)

\section{Produtividade}

As subcategorias de produtividade sugerem que há uma importância diferente das atividades nos dois grupos.

De forma geral o "trabalho" é um item importante em ambos os grupos, mas pode estar relacionado ao próximo item, "tarefas domésticas", temos que apenas $28,4 \%$ das mulheres com DPC, em nosso trabalho, estão inseridas no mercado de trabalho, ou seja, ficando susceptíveis a se importarem mais com as atividades do lar. Dentro do contexto ocupacional da mulher de classe média/baixa está historicamente relacionado à importância das mulheres em realizarem essas atividades no âmbito familiar (Pena, 1981), além disso, estudos mostram que mulheres com dores crônicas apresentam muita dificuldade em desempenhar essas atividades, por acreditarem ser importantes utilizam estratégias para conseguir realiza-las (Morden, Jinks e Ong, 2015).

"Eu trabalho em pé, então eu preciso ficar em pé, mas é difícil, parece que lateja, não sei, quando consigo sentar piora, é difícil viu!' (Individuo 50 - grupo "dor") 
"... Ah... eu fico em casa sozinha, às vezes estou com dor durante o dia e passo dormindo e de noite levanto da cama para lavar louça ou ajeitar as coisas da casa” (Indivíduo 39 - grupo "dor”)

"Gosto de fazer comida, não faço mais e quando faço minha filha ajuda, mas nada melhor que uma comida feita ali na hora..." (Indivíduo 48 - grupo "dor")

O último item, "deveres", está em menor número nas mulheres do grupo "dor", esse resultado segundo estudo encontrado pode ser explicado pelo fato de que indivíduos com dores crônicas apresentam muitos conflitos familiares e dificuldades em se relacionar com indivíduos do âmbito familiar, ou próximos a ele no dia-a-dia (Mcnamee e Mendolia, 2014). Além disso, outros trabalhos sugerem que a dor crônica causa dificuldades em seus deveres, como levar os filhos na escola; isso porque a dor Ihes causa cansaço, energia limitada e maior necessidade de descanso (Michaëlis, Kristiansen e Norredam, 2015).

"... Eu peço para minha filha buscar meu menor na escola, as vezes ele vem sozinho." (Indivíduo 35 - grupo "dor")

"Minha mãe fica comigo, ela tem problema sabe, mas as vezes eu fico deitada do lado dela, pra poder olhar, mas a vontade que eu tenho é de ficar longe dela, mas fazer o que ela só tem eu" (Indivíduo 42 - grupo "dor") 


\section{Lazer}

As análises da categoria "lazer" e suas subcategorias "recreação tranquila", "recreação ativa" e "socialização" apresentam um resultado de importância parecida entre os dois grupos. Michaëlis, 2015, em sua entrevista de mulheres com dor pélvica crônica, coloca que tarefas como uma caminhada se torna dificil devido a dor e a interação social com outros individuos se desgastam com o passar do tempo (Michaëlis, Kristiansen e Norredam, 2015).

"Eu passo o dia inteiro deitada, não quero fazer nada, fico deitada para não piorar a dor, parece que só de levantar dói, às vezes ligo a TV para não tentar pensar na dor?" (Individuo 19 - grupo "dor")

"Eu bordo chinelo, como eu fico muito tempo deitada para não ficar parada eu bordo, ai eu vendo" (Individuo 47 - grupo "dor")

As atividades discriminadas são relevantes para preencher possíveis lacunas do quanto a DPC interfere nas grandes áreas ocupacionais dessas mulheres e com base nessa discussão anterior, observa-se o comportamento dessas mulheres e aqui fazemos uma comparação ao comportamento de indivíduos com dores crônicas que estão frequentemente associados a isolamento social (Strand et al., 2015), os laços sociais são importantes para a evolução humana e evidencias sugerem que são importantes para a saúde (Cacioppo e Cacioppo, 2014), em estudo recente em nossa equipe com mulheres com DPC e endometriose sugere a presença de isolamento social nos relatos da entrevista (Mellado, 2015), de forma geral mulheres que apresentam dores crônicas revelam que a dor interfere nas habilidades de criar e manter relações 
sociais, além disso, a perda de relações sociais, como até mesmo o trabalho, e a incapacidade funcional física restrita, devido à dor, tornaram as mulheres incapazes de manter atividades de lazer, convidar amigos e família para reuniões ou de se envolver em outras atividades sociais, formando um ciclo de isolamento social desses indivíduos (Michaëlis, Kristiansen e Norredam, 2015); perda de identidade (self) (Charmaz, 1983), normalmente os indivíduos constroem sua identidade a partir de suas experiências ao longo da vida, o individuo que apresenta dor crônica perde essa autoimagem que foi construída ao longo do tempo, isso ocorre devido a dor física, o desconforto psicológico e aos efeitos dos procedimentos médicos que causam ao longo da doença; mecanismos de enfrentamento (coping) (O'toole, Connolly e Smith, 2013; Ciaramella e Poli, 2015), sabe-se atualmente que os indivíduos utilizam de diferentes formas de lidar e enfrentar a dor (Nelson e Churilla, 2015), mulheres com dor crônica apresentam diversas formas de enfrentamento, como: alterar as atividades do cotidiano conforme a dor aparece, limitando algumas atividades físicas e mantendo uma rotina de suas atividades diárias mínimas, uso de medicamentos, descanso, uso de calor para alívio de dor e ajuda de terceiros (Michaëlis, Kristiansen e Norredam, 2015); e dor social, (Eisenberger, 2012), que pode ser definida como uma experiência desagradável que é associada a um dano real ou potencial para a interação social ou valor social (devido à rejeição social, a exclusão, a avaliação social negativa do individuo ou perda), a dor social vem sendo estudada cada vez mais, é comparada a dor física devido ser representada pela mesma região cerebral, sabe-se que ambos os tipos de dor são angustiantes e os indivíduos apresentam várias emoções parecidas (medo, tristeza, raiva, ansiedade e 
vergonha) (Kross et al., 2011). A dor crônica acarreta no individuo comportamentos que muitas vezes indivíduos que não estão passando pela mesma dificuldade ou não entendem a situação de cronicidade do doente acabam se afastando, reforçando ainda mais 0 isolamento que o próprio individuo iniciou, acarretando em um isolamento social (Marquez, 2011; Michaëlis, Kristiansen e Norredam, 2015). 


\section{Considerações finais}

O desempenho e a satisfação de mulheres com DPC são prejudicados devido, principalmente, a DPC. A condição ocupacional, como podemos observar em nossa pesquisa e outros trabalhos aqui apresentados, pode ser afetada pela condição de dor crônica nos indivíduos, porém trabalhos específicos em relação à dor pélvica crônica e desempenho ocupacional, com o nosso, devem ser desenvolvidos para abertura de novas hipóteses.

As mulheres com DPC estão em menor número no mercado de trabalho do que mulheres saudáveis, fator que pode interferir nas atividades consideradas importantes para as mulheres com DPC, na literatura estudada não foi encontrado nada sobre esta relação. Além disso, as alterações no sono e cirurgia abdominais anteriores, estão presentes em maior número em mulheres com DPC, a relação dessas duas características com indivíduos com dores crônicas devem ser aprofundadas.

Podemos observar que mulheres com DPC apresentam um comportamento em relação à doença de maneira parecida a outros indivíduos com dores crônicas, como a perda de identidade, isolamento social, coping e dor social.

Nosso resultado do questionário TAMPA sugere que mulheres com DPC apresentam medo ao realizar suas atividades, mas outras pesquisas devem ser realizadas para afirma este tipo de relação.

Nosso trabalho tenta preencher uma lacuna na literatura sobre o desempenho ocupacional em mulheres portadoras de dor pélvica crônica, pouco se sabe sobre a doença, mas pôde-se observar com nossa pesquisa que há uma 
interferência no desempenho ocupacional dessas mulheres, além do fato que essas mulheres apresentam uma tendência de sentir medo ao realizarem suas atividades. 


\section{Bibliografia}

AMERICAN PSYCHIATRIC ASSOCIATION. Diagnostic and statistical manual of mental disorders. Washington (DC): American Psychiatric Association, 1994.

Diagnostic and statistical manual of mental disorders. $4^{\circ}$. Washington: American Psychiatric Association, 2002.

ANDREW WALSH, D. et al. Performance problems of patients with chronic low-back pain and the measurement of patient-centered outcome. Spine, v. 29, n. 1, p. 87-93, Jan 2004.

BARCELOS, P. R. et al. Quality of life of women with chronic pelvic pain: a cross-sectional analytical study. Revista Brasileira de Ginecologia e Obstetrícia, v. 32, n. 5, p. 247-53, May 2010.

BECK, A.; ALFORD, B. O poder integrador da terapia cognitiva. Porto Alegre Artmed, 2000.

BLYTH, F. M. et al. Chronic pain, work performance and litigation. Pain, v. 103, n. 1-2, p. 41-7, May 2003.

BORGES, L. H.; MEDRADO, M. A. Transtornos mentais menores entre trabalhadores de uma usina siderúrgica. Revista Brasileira de Saúde Ocupacional, v. 21, n. 77, p. 7-18, 1993.

BOTTEGA, F. H.; FONTANA, R. T. A dor como quinto sinal vital: utilização da escala de avaliação por enfermeiros de um hospital geral. Texto \& Contexto Enfermagem, Florianópolis, v. 19, n. 2, p. 283-90, 2010.

BREIVIK, $\mathrm{H}$. et al. Survey of chronic pain in Europe: prevalence, impact on daily life, and treatment. European Journal Pain, v. 10, n. 4, p. 287-333, May 2006.

BRODER, M. S. et al. The appropriateness of recommendations for hysterectomy. Obstetrics \& Gynecology, v. 95, n. 2, p. 199-205, Feb 2000. 
CACIOPPO, J. T.; CACIOPPO, S. Social Relationships and Health: The Toxic Effects of Perceived Social Isolation. Social and Personality Psychology Compass, v. 8, n. 2, p. 58-72, Feb 2014.

CALDAS, A. S. C.; FACUNDES, V. L. D.; SILVA, H. J. Using the Canadian Occupational Performance Measure in Brazilian studies: a systematic review. Revista de Terapia Ocupacional da Universidade de São Paulo, v. 22, n. 3, p. 238-244, 2011.

CARSWELL, A. et al. The Canadian Occupational Performance Measure: a research and clinical literature review. Can J Occup Ther, v. 71, n. 4, p. 21022, Oct 2004.

CHAPPARO, C.; RANKA, J. The Occupational Performance Model (Australia): A description of constructs and structure. Australia: The University of Sidney, p. 1-22, 1997.

CHARMAZ, K. Loss of self: a fundamental form of suffering in the chronically ill. Sociol Health IIIn, v. 5, n. 2, p. 168-95, Jul 1983.

CHEONG, Y.; WILLIAM STONES, R. Chronic pelvic pain: etiology and therapy. Best Practice 7 Research Clinical Obstetrics \& Gynaecology, v. 20, n. 5, p. 695-711, Oct 2006.

CIARAMELlA, A.; POLI, P. Chronic Low Back Pain: Perception and Coping With Pain in the Presence of Psychiatric Comorbidity. J Nerv Ment Dis, v. 203, n. 8, p. 632-40, Aug 2015.

CROMBIE, I. et al. Epidemiology of pain. International Association for the Study of Pain Press, Seattle, 1999.

DE CARLO, M. M. R.; BARTALOTTI, C. C. Caminhos da Terapia Ocupacional. In: DE CARLO, M. M. R. e BARTALOTTI, C. C. (Ed.). Terapia Ocupacional no Brasil: Fundamento e perspectivas. São Paulo: Editora Plexus, 2001.

DE CARLO, M. M. R. P.; ELUI, V. M. C.; PACKER, M. P. Terapia ocupacional e atenção a pacientes com dor não-oncológica. In: DE CARLO, M. M. R. P.;ELUI, V. M. C., et al (Ed.). Dor e cuidados paliativo - Terapia ocupacional e interdisciplinaridade. 1. São Paulo: Roca, 2008. cap. 8, p.167-190.

DE LIMA OSÓRIO, F. et al. Study of the discriminative validity of the PHQ-9 and PHQ-2 in a sample of Brazilian women in the context of primary health care. Perspectives in Psychiatric Care, v. 45, n. 3, p. 216-27, Jul 2009. 
DE SOUZA, F. S. et al. Psychometric testing confirms that the BrazilianPortuguese adaptations, the original versions of the Fear-Avoidance Beliefs Questionnaire, and the Tampa Scale of Kinesiophobia have similar measurement properties. Spine, v. 33, n. 9, p. 1028-33, Apr 2008.

DELLAROZA, M. S. G.; PIMENTA, C. A. D. M.; MATSUO, T. Prevalência e caracterização da dor crônica em idosos não institucionalizados Caderno de Saúde Pública, Rio de Janeiro, v. 23, n. 5, 2007.

DEUS, J. M. et al. Analysis of 230 women with chronic pelvic pain assisted at a public hospital. Revista Dor, São Paulo, v. 15, n. 3, p. 191-7, 2014.

EISENBERGER, N. I. The pain of social disconnection: examining the shared neural underpinnings of physical and social pain. Nature Reviews Neuroscience, v. 13, n. 6, p. 421-34, Jun 2012.

ELLIOTT, A. M. et al. The epidemiology of chronic pain in the community. The Lancet, v. 354, n. 9186, p. 1248-52, Oct 1999.

FISHBAIN, D. A. The association of chronic pain and suicide. Semin Clin Neuropsychiatry, v. 4, n. 3, p. 221-7, Jul 1999.

FLECK, A. C.; WAGNER, A. A mulher como a principal provedora do sustento econônomico familiar. Psicologia em estudo, v. 8, p. 31-38, 2003.

GRACE, V. M.; ZONDERVAN, K. T. Chronic pelvic pain in New Zealand: prevalence, pain severity, diagnoses and use of the health services. Australian and New Zealand Journal of Public Health, v. 28, n. 4, p. 369-75, 2004.

GUREJE, O. et al. Persistent pain and well-being: a World Health Organization Study in Primary Care. JAMA, v. 280, n. 2, p. 147-51, Jul 81998.

GUYTON, A. C.; HALL, J. E. Sensações somáticas:Il dor, cefaleia e sensações térmicas. In: GUYTON, A. C. e HALL, J. E. (Ed.). Tratado de fisiologia médica. 10. Rio de Janeiro: Guanabara Koogan, 2002. cap. 48,

HADJISTAVROPOULOS, T. et al. Transforming long-term care pain management in north america: the policy-clinical interface. Pain Med, v. 10, $\mathrm{n}$. 3, p. 506-20, Apr 2009. 
HAGGERTY, C. L. et al. Lower quality of life among women with chronic pelvic pain after pelvic inflammatory disease. Obstet Gynecol, v. 102, n. 5 Pt 1, p. 934-9, Nov 2003.

HARDING, T. W. et al. Mental disorders in primary health care: a study of their frequency and diagnosis in four developing countries. Psychological medicine, v. 10, p. 231-41, 1980.

HOWARD, F. M. Chronic pelvic pain. Obstetetrics \& Gynecology, v. 101, n. 3, p. 594-611, Mar 2003.

KROENKE, K. et al. An ultra-brief screening scale for anxiety and depression: the PHQ-4. Psychosomatics, v. 50, n. 6, p. 613-21, 2009 Nov-Dec 2009.

KROSS, E. et al. Social rejection shares somatosensory representations with physical pain. Proceedings of the National Acadamy of Sciences, v. 108, $\mathrm{n}$. 15, p. 6270-5, Apr 2011.

LAMÉ, I. E. et al. Test--retest stability of the Pain Catastrophizing Scale and the Tampa Scale for Kinesiophobia in chronic pain over a longer period of time. Journal of Health Psychology, v. 13, n. 6, p. 820-6, Sep 2008.

LATTHE, P. et al. WHO systematic review of prevalence of chronic pelvic pain: a neglected reproductive health morbidity. BMC Public Health, v. 6, p. 177, 2006.

LAW, M. Client-centered occupational therapy. New York: Slack, 1998.

Medida canadense de desempenho ocupacional (COPM). Magalhães, L.Magalhães, L.Cardoso, A. . Belo Horizonte: 2009.

LOESER, J. D.; TREEDE, R.-D. The Kyoto protocol of IASP Basic Pain Terminology. Pain, v. 137, n. 3, p. 473-7, Jul 2008.

LÜNING BERGSTEN, C. et al. Change in kinesiophobia and its relation to activity limitation after multidisciplinary rehabilitation in patients with chronic back pain. Disability and Rehabilitation, v. 34, n. 10, p. 852-8, 2012.

MAGALHÃES, L. C.; MAGALHÃES, L. V.; CARDOSO, A. A. Medida canadense de Desempenho ocupacional (COPM). Belo Horizonte: Editora UFMG, 2009. 
MAGNI, G. et al. Chronic musculoskeletal pain and depressive symptoms in the general population. An analysis of the 1st National Health and Nutrition Examination Survey data. Pain, v. 43, n. 3, p. 299-307, Dec 1990.

MARCHAND, S. The physiology of pain mechanisms: from the periphery to the brain. Rheumatic Disease Clinics of North America, v. 34, n. 2, p. 285-309, May 2008.

MARI, J. J.; WILLIAMS, P. A validity study of a psychiatric screening questionnaire $(S R Q-20)$ in primary care in the city of Sao Paulo. $\mathbf{B r} \mathbf{J}$ Psychiatry, v. 148, p. 23-6, Jan 1986.

MARQUEZ, J. O. A dor e os seus aspecto multidimensionais. Ciência e Cultura, São Paulo, v. 63, 2011.

MATHIAS, S. D. et al. Chronic pelvic pain: prevalence, health-related quality of life, and economic correlates. Obstetrics \& Gynecology, v. 87, n. 3, p. 321-7, Mar 1996.

MCNAMEE, P.; MENDOLIA, S. The effect of chronic pain on life satisfaction: evidence from Australian data. Social Science \& Medicine, v. 121, p. 65-73, Nov 2014.

MELLADO, B. H. F., ANANDA C. M. POLI-NETO, OMERO B. ROSA E SILVA, JULIO C. NOGUEIRA, ANTONIO A. CANDIDO-DOS-REIS, FRANCISCO J. Social isolation in women with endometriosis and chronic pelvic pain. International Journal of Gynecology \& Obstetrics, 2015.

MERSKEY, H.; BOGDUK, N. Classification of chronic pain: descriptions chronic pain syndromes and definitions of pain terms prepared by the International Association for the Study of Pain. IASP Press, Seattle, 1994.

Classification of Chronic Pain. 2. Seattle: IASP Press, 2011. 209-214.

MICHAËLIS, C.; KRISTIANSEN, M.; NORREDAM, M. Quality of life and coping strategies among immigrant women living with pain in Denmark: a qualitative study. BMJ Open, v. 5, n. 7, p. e008075, 2015.

MORDEN, A.; JINKS, C.; ONG, B. N. Risk and self-managing chronic joint pain: looking beyond individual lifestyles and behaviour. Sociology of Health \& IIIness, v. 37, n. 6, p. 888-903, Jul 2015. 
MOULIN, D. E. et al. Chronic pain in Canada--prevalence, treatment, impact and the role of opioid analgesia. Pain Res Manag, v. 7, n. 4, p. 179-84, 2002.

MÂNGIA, E. F. Contributions of the canadian's approach "client-centered occupational therapy" and of the italian's deinstitutionalization authors for the occupational therapy in mental health. Revista de Terapia Ocupacional da Universidade de São Paulo, v. 13, n. 3, p. 127-134, 2002.

NELSON, N.; CHURILLA, J. R. Physical activity, fear avoidance, and chronic non-specific pain: A narrative review. J Bodyw Mov Ther, v. 19, n. 3, p. 494-9, Jul 2015.

NICKEL, R. et al. Quality of life issues and occupational performance of persons with epilepsy. Arquivos de Neuro-Psiquiatria, v. 70, n. 2, p. 140-4, Feb 2012.

NOGUEIRA, A. A.; REIS, F. J. C.; POLI NETO, O. B. Management of chronic pelvic pain in women. Revista Brasileira de Ginecologia e Obstetrícia, Rio de Janeiro, v. 28, n. 12, 2006.

NUNES, C. M. P. Dor neuromusculoesquelética. In: KOOGAN, G. (Ed.). Terapia Ocupacional: fundamentação \& prática. Rio de Janeiro, 2007. cap. 27, p.258 - 270.

O'TOOLE, L.; CONNOLLY, D.; SMITH, S. Impact of an occupation-based selfmanagement programme on chronic disease management. Australian Occupational Therapy Journal, v. 60, n. 1, p. 30-8, Feb 2013.

PENA, M. V. J. Mulheres e trabalhadoras: presença feminina na constituição do sistema fabril. Rio de Janeiro: Paz e terra, 1981.

PERNEROS, G.; TROPP, H.; SANDQVIST, J. Evaluation of occupational performance and pain intensity: before and after back surgery and rehabilitation. Scandinavian Journal of Occupational Therapy, v. 21, n. 1, p. 69-81, Jan 2014.

PERSSON, E.; RIVANO-FISCHER, M.; EKLUND, M. Evaluation of changes in occupational performance among patients in a pain management program. Journal of Rehabilitation Medicine, v. 36, n. 2, p. 85-91, Mar 2004.

PESUDOVS, K.; CRAIGIE, M. J.; ROBERTON, G. The visual analogue scale for the measurement of pain is not linear. Anaesthesia and Intensive Care Journal, v. 33, n. 5, p. 686-7; Oct 2005. 
PITTS, M. K. et al. Prevalence and correlates of three types of pelvic pain in a nationally representative sample of Australian women. Medical Journal of Australia, v. 189, n. 3, p. 138-43, Aug 2008.

ROELOFS, J. et al. The Tampa Scale for Kinesiophobia: further examination of psychometric properties in patients with chronic low back pain and fibromyalgia. European Journal of Pain, v. 8, n. 5, p. 495-502, Oct 2004.

ROMAO, A. P. et al. Chronic pelvic pain: multifactorial influences. Journal of Evaluation in Clinical Practice, v. 17, n. 6, p. 1137-9, Dec 2011.

SBED - SOCIEDADE BRASILEIRA PARA O ESTUDO DA DOR. Classificação de dor. Acesso em: 10 de abril.

SILVA, G. P. O. G. et al. High prevalence of chronic pelvic pain in women in Ribeirao Preto, Brazil and direct association with abdominal surgery. Clinics, v. 66, n. 8, p. 1307-1312, 2011.

SILVEMARK, A. J. et al. Life satisfaction in patients with long-term nonmalignant pain-relation to demographic factors and pain intensity. Disability and Rehabilitation, v. 30, n. 25, p. 1929 - 37, 2008.

SIQUEIRA, J. T. T. D. Porque a dor é uma questão também de saúde pública. Sociedade brasileira para o estudo da dor, São Paulo, 2014.

SOUSA, F. A. E. F. Dor: o quinto sinal vital. Revista Latino Americana Enfermagem, Ribeirão Preto, v. 10, n. 3, 2002.

SPECIALI, J. G.; GONÇALVES, D. A. D. G. Classificação, fisiopatologia e epidemiologia da dor. In: DE CARLO, M. M. R. D. P. e QUEIROZ, M. E. G. D. (Ed.). Dor e cuidados paliativos - terapia ocupacional e interdisciplinaridade. 1. São Paulo: Roca, 2008. cap. 2, p.28-61.

STEGLITZ, J.; BUSCEMI, J.; FERGUSON, M. J. The future of pain research, education, and treatment: a summary of the IOM report "Relieving pain in America: a blueprint for transforming prevention, care, education, and research". Translational Behavioral Medicine, v. 2, n. 1, p. 6-8, Mar 2012.

STRAND, V. et al. Patient Expectations and Perceptions of Goal-setting Strategies for Disease Management in Rheumatoid Arthritis. The Journal of Rheumatology, Aug 2015. 
STRONG, J. et al. Pain: a textbook for therapists. United Kingdom: Livingstone C., 2002.

SÁ, K. N. et al. Chronic pain and gender in Salvador population, Brazil. Pain, v. 139, n. 3, p. 498-506, Oct 2008.

TEIXEIRA, M. J. Chronic pain and depression. Revista Neurociências, v. 14, n. 2, p. 44-53, 2006.

TENG, C. T.; HUMES, E. D. C.; DEMETRIO, F. N. Depression and medical comorbidity. Revista Psiquiátrica Clínica, v. 32, n. 3, p. 149-159, 2005.

THE CANADIAN PAIN SOCIETY. Pain is poorly managed in Canada. 2014.

TOWNSEND, E.; BRINTNELL, S.; STAISEY, N. Developing guidelines for client-centred occupational therapy practice. Can J Occup Ther, v. 57, n. 2, p. 69-76, Apr 1990.

VAN HUET, H.; INNES, E.; STANCLIFFE, R. Occupational therapists perspectives of factors influencing chronic pain management. Aust Occup Ther J, v. 60, n. 1, p. 56-65, Feb 2013.

VON KNORRING, L. et al. Pain as a symptom in depressive disorders. I. Relationship to diagnostic subgroup and depressive symptomatology Pain, v. 15, n. 1-4, p. 19-26, 1982.

WARREN, J. W.; MOROZOV, V.; HOWARD, F. M. Could chronic pelvic pain be a functional somatic syndrome? American Journal of Obstetrics \& Gynecology, v. 205, n. 3, p. 199.e1-5, Sep 2011.

ZANNI, K. P.; BIANCHIN, M. A.; MARQUES, L. H. N. Qualidade de vida e desempenho ocupacional de pacientes

submetidos à cirurgia de epilepsia. Journal of Epilepsy and Clinical Neuropshysiology, v. 15, n. 3, p. 114-117, 2009.

ZONDERVAN, K.; BARLOW, D. H. Epidemiology of chronic pelvic pain. Best Practice \& Research: Clinical Obstetetrics \& Gynaecology, v. 14, n. 3, p. 403-14, 2000. 
ZONDERVAN, K. T. et al. The community prevalence of chronic pelvic pain in women and associated illness behaviour. British Journal of General Practice, v. 51, n. 468, p. 541-7, Jul 2001. 
Anexos

Anexo 1. Escala Visual Analógica - EVA e Escala de Faces

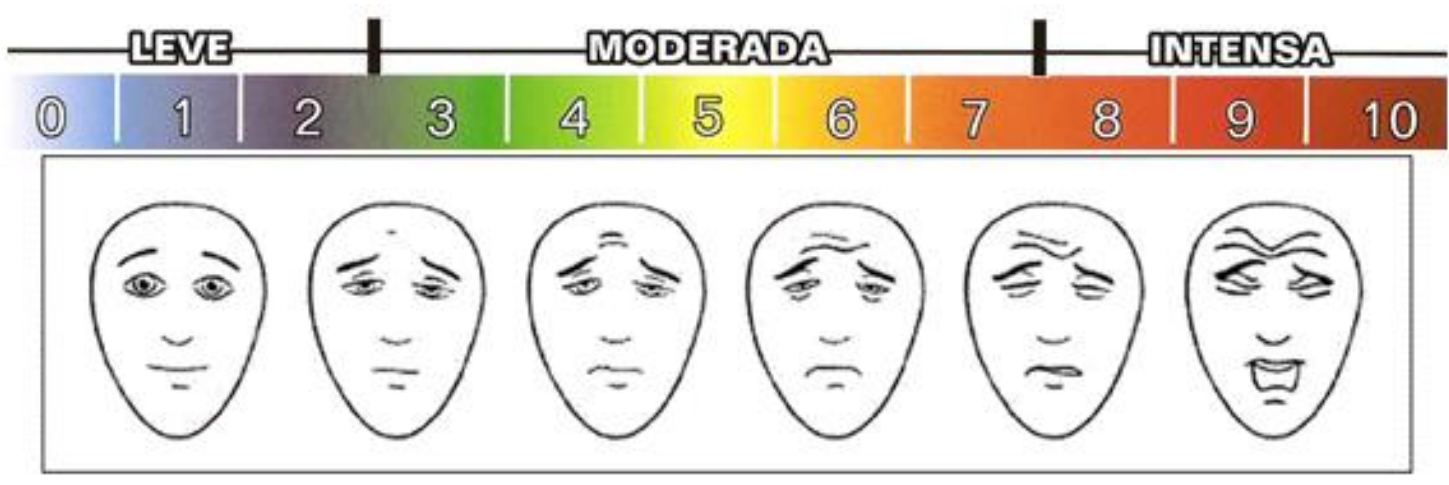


Anexo 2. Patient Health Questionnaire (PHQ-4)

\section{Patient Health Questionnaire (PHQ-4)}

Nome do (a) paciente:

\begin{tabular}{|c|c|c|c|c|}
\hline \multicolumn{5}{|c|}{$\begin{array}{l}\text { QUESTIONARIO SOBRE A S A ÚDE DO/A PACIENTE-4 } \\
\text { (Portuguese for Brazil version of the PHQ-4) }\end{array}$} \\
\hline $\begin{array}{l}\text { Durante as últimas } 2 \text { semanas, com que freqüência você } \\
\text { foi incomodado/a por qualquer um dos problemas } \\
\text { abaixo? }\end{array}$ & Nenhuma vez & Váries dias & $\begin{array}{c}\begin{array}{c}\text { Mats da } \\
\text { metade dos } \\
\text { dias }\end{array} \\
\end{array}$ & $\begin{array}{l}\text { Quase todos } \\
\text { os dias }\end{array}$ \\
\hline 1. Pouco interesse ou pouco prazer em: fazer as coisas & 0 & 1 & 2 & 3 \\
\hline 2. Se sentir "para baixo", ceprimicóa ot sem perspectiva & 0 & 1 & 2 & 3 \\
\hline 3- Se sentir nervoso, ansioso ou inquieto & 0 & 1 & 2 & 3 \\
\hline 4- Não ser capaz de parar ou controlar preocupaçães & 0 & 1 & 2 & 3 \\
\hline Ptizer linc. Todos os dir & & & PHYSP & \\
\hline
\end{tabular}

Kroenke, K., Sp̧itzer, R. L., \& Wellians, J. B. (2003). The Pattent Health Questieriaire-2: validity of a twe-tem depression screener. Med Care, 4i, 1284-1292.

De Lima Osórie, F., Vilela Mendes, A., Crişpa, J.A., \& Loureiro, S.R. (2009). Study of the discriminative validity of the PHQ-9 and PHQ-2 in a sample ef Brazilian women in the context of primary heath care. Perspect Psyckiatr Care, 45, 216-227.

Löwe B, Wabl I, Rese M, Spetzer C, Glacsmer H, Wingenfetd K, Schneider A, Brabler E. A 4-item: measure of depression and arxiety: validation and standardization of the Patient Heath Questioniatre-4 (PHQ 4 ) in the general population. \& Affect Disord. 2010 A.pr; 122(1-2):86-95. Epevo 2009 Jil 17. 


\section{Anexo 3. Self Report Questionnarie}

SRQ

O(A) SR(A). PODERIA POR FAVOR, RESPONDER ÀS SEGUINTES PERGUNTAS A RESPEITO DA SUA SAÚDE: पL

\begin{tabular}{|c|c|c|}
\hline 01- Tem dores de cabę̧a frequüentes? & $1-\operatorname{Sim}$ & 2- NẼo \\
\hline 02- Tem falta de apetite? & 1- Sim & 2- NẼ \\
\hline 03- Dorme mal? & $1-\operatorname{Sim}$ & 2- NẼo \\
\hline 04- Assustz-se com facilidade? & 1-Sim & $2-\mathrm{N} 2 \mathrm{O}$ \\
\hline 05- Tem tremores áe raào? & $1-\operatorname{Sim}$ & 2- NEO \\
\hline 06- Sente-se rervoso(a), tenso(a) or preocupado(a) & $1-\operatorname{Sim}$ & 2- Nao \\
\hline 07- Tem mé đ́igestàs? & 1-Sim & 2- NẼo \\
\hline 08- Tem difieulfafe de pensar cont elareza? & $1-\operatorname{Sim}$ & 2- NẼo \\
\hline 09- Tem se sentía triste uítimemente? & 1- $\operatorname{Sim}$ & 2- NEO \\
\hline 16- Tem choraco mais co que de costume? & $1-\operatorname{Sim}$ & 2- NEO \\
\hline 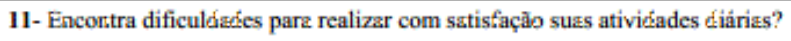 & 1-Sim & 2- NEO \\
\hline 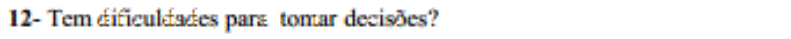 & $1-\operatorname{Sim}$ & 2- NEO \\
\hline 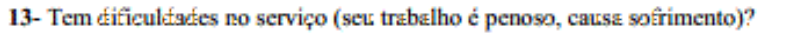 & $1-\operatorname{Sim}$ & 2- NEO \\
\hline 14- É incapaz de desempenhar um peppel útil en sua vida? & 1-Sim & 2- NEo \\
\hline 15- Tem perdifo o interesse pelas coisas? & $1-\operatorname{Sim}$ & 2- NEO \\
\hline 16-Vocè se serte uma pessaa int́til, sem préstimo? & $1-\operatorname{Sim}$ & $2-\mathrm{N} 20$ \\
\hline 17-Tem tido idéias de aceber com a vífa & 1- $\operatorname{Sim}$ & 2- NEo \\
\hline 18- Sente-se cansado(z) c tempo tedo? & 1- Sim & 2- NEo \\
\hline 19- Tem sersạ̧̉̃es desagradżveis no estômago? & $1-\operatorname{Sim}$ & 2- NẼo \\
\hline 20- Vooê se carsz com facilickade? & 1-Sim & 2- N2o \\
\hline
\end{tabular}

\section{A - Total de sim L L |}

\begin{tabular}{|c|c|c|}
\hline 21- Sente que tem algrém: que de alguma maneira qter the tezzer mal? & 1. Sim & 2- Não \\
\hline 22- Você é đlguém muito mais impertante do q̨ue a maioria das pessoas perssa? & 1- Sim & 2- Nãc \\
\hline 23- Tem notado algtma irterferércia ot outro préblema estrantso cí seu perssartento? & 1- Sim & 2- Não \\
\hline 24- Cuve vozes que não sabe de onde vêm, ou que cutras pessoas nào podem ouvir? & 1- Sim & 2- Nãc \\
\hline
\end{tabular}

B - Total de sim Lال_ L

Harditing TW, Arango MV, Baltazar $\mathbf{J}$ et al. Mestal disorders in primary heatth care: a study of their frequency and diagnosis in four developing countries. Psychol Med 1986;10:231-41.

Mari JJ, Williams P. A validity study of a psychiatric screening questionnaire (SRQ-20) in primtazy care in the city of Sae Paule. Br J Psychiat:y. 1986 Jan;148:23-6. 
Anexo 4. Escala Tampa para Cinesiofobia

Escala Tampa para Cinesiofobia

Aqui estão algumas das coisas que outros pacientes nos contaram sobre sua dor. Para cada aftrmativa, por favor, indique um numero de 1 a 4 , caso você concorde ou discorde da afirmativa. Primeiro você vai pensar se concorda ou discorda e depois, se totalmente ou parcialmente.

\begin{tabular}{|c|c|c|c|c|}
\hline & $\begin{array}{l}\text { Discordo } \\
\text { totalmente }\end{array}$ & $\begin{array}{l}\text { Discordo } \\
\text { parcialmente }\end{array}$ & $\begin{array}{l}\text { Concordo } \\
\text { parcialmente }\end{array}$ & $\begin{array}{l}\text { Concordo } \\
\text { totalmente }\end{array}$ \\
\hline $\begin{array}{l}\text { 1. Eu tenho mado que eu possa mie mactucar se eu } \\
\text { fizer exercicios. }\end{array}$ & $\hat{f}$ & 2 & 3 & 4 \\
\hline $\begin{array}{l}\text { 2. Se eu tents sse superar esse medo, minha do? } \\
\text { aumertania. }\end{array}$ & 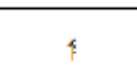 & 2 & 3 & 4 \\
\hline $\begin{array}{l}\text { 3. Met: corpo está me dizendo que algo muito errado } \\
\text { esta asortesendo comigo. }\end{array}$ & $f$ & 2 & 3 & 4 \\
\hline $\begin{array}{l}\text { 4. Minha dor provivelriente seris alvisisda se eu fizesse } \\
\text { exercizio. }\end{array}$ & $f$ & 2 & 3 & 4 \\
\hline $\begin{array}{l}\text { 5. As pessoas não estăo levando minha condição } \\
\text { miédica a serio. }\end{array}$ & 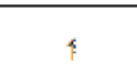 & 2 & 3 & 4 \\
\hline $\begin{array}{l}\text { 6. Minha lesão colocou o meu corpo em: insco para o } \\
\text { resto ds mirha vida. }\end{array}$ & 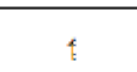 & 2 & 3 & 4 \\
\hline 7. A dor sempre significa que eu ma chuquei mel corpo. & $\hat{k}$ & 2 & 3 & 4 \\
\hline $\begin{array}{l}\text { 8. Ś́ porque aliguma coist pixra minha dor, ñ̃o } \\
\text { significa que è perigoso. }\end{array}$ & $\hat{f}$ & 2 & 3 & 4 \\
\hline $\begin{array}{l}\text { 9. Eli fenho medo que eu possa rra mactucar } \\
\text { adidentalr:ente. }\end{array}$ & \{ & 2 & 3 & 4 \\
\hline 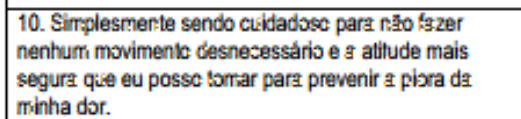 & 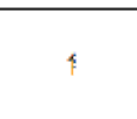 & 2 & 3 & 4 \\
\hline $\begin{array}{l}\text { 11. Eu não teria tanta dor se alşo potencialmente } \\
\text { perigoso nåo estivesse aczntecendo ro meu corpo. }\end{array}$ & $\hat{\beta}$ & 2 & 3 & 4 \\
\hline 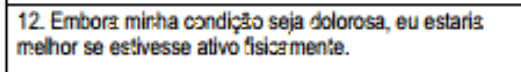 & $\hat{t}$ & 2 & 3 & 4 \\
\hline $\begin{array}{l}\text { 13. A dor mre avist cuando parar o exercicio para que } \\
\text { eu năo me machuque. }\end{array}$ & $\mathrm{f}$ & 2 & 3 & 4 \\
\hline 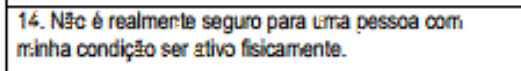 & 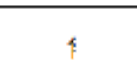 & 2 & 3 & 4 \\
\hline $\begin{array}{l}\text { 15. Eu não posso fazer lodas as coisas que đss pessogs } \\
\text { normais fazem, porque para mim e mutilo fádl me } \\
\text { mæchucar. }\end{array}$ & $f$ & 2 & 3 & 4 \\
\hline $\begin{array}{l}\text { 16. Embors algo esteja me csusando mulita dxx, elc não } \\
\text { acho que sejs, de fato, perigoso. }\end{array}$ & $f$ & 2 & 3 & 4 \\
\hline $\begin{array}{l}\text { 17. Nirguém devería 'azer exercicios, quando estats com } \\
\text { dor. }\end{array}$ & $\hat{f}$ & 2 & 3 & 4 \\
\hline
\end{tabular}


Anexo 5. Medida Canadense de Desempenho Ocupacional (COPM)

\section{MEDIDA CANADENSE DE DESEMPENHO OCUPACIONAL (COPM)' \\ Segunda Edição}

Autores: Mary Law, Sue Baptiste, Ame Carswell, Mary Ann Mccoll, Helene Polatako, Nano Pollod²

Nome do diente:
Entrevistado:
sen non foco odertel
Terape uta:
Cinica/Hospitd:

Registro ño:
Data prevista para reavaliaçáa:
Data da reavaliaçăa:

PASSO 1: IDENTIFICACÃO DE QUESTÕES NO DESEMPENHO OCUPACIONAL

Para idenffica problemos, preouporộes e questôs relatives os desempento oapacional, enteriste o diente questionando

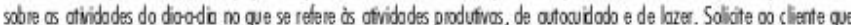
identibque os atvidades do dioo-dia que quer realiza, que nexessita realizar ou que é esperodo que ele realize, encoripno.

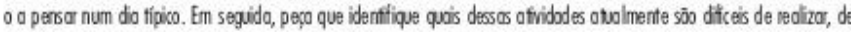
forno satisfototion. Registre estes atividodes problemátices nos Possos IA, IB ou IC.

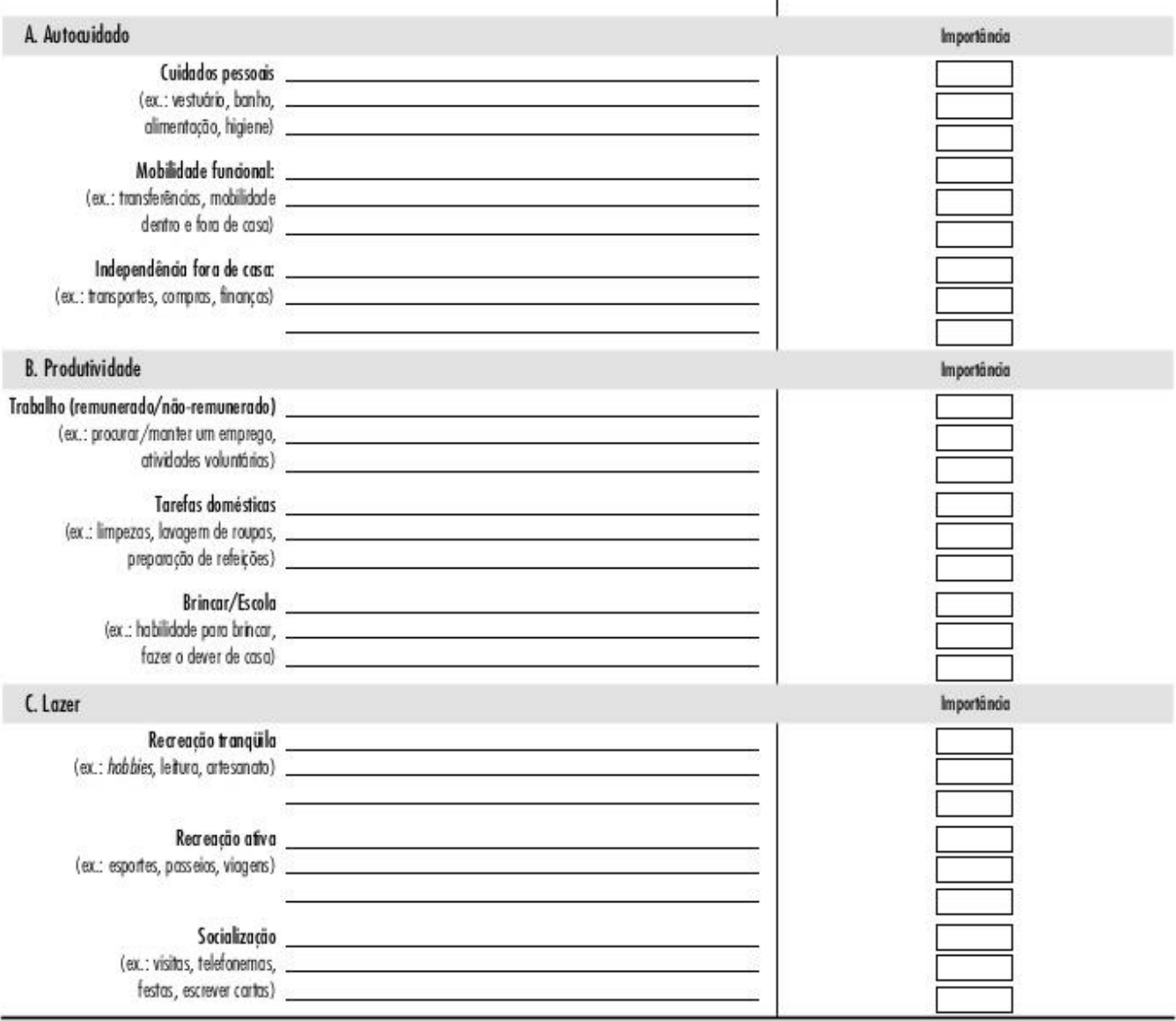

PASSO 2: CLASSIFICAC̄AO DO GRAU DE IMPORTÂNCIA auma escala de 1 a 10, a impatincio de coda atividode. Cologue as pontuox, ôes nos respectivos quodrodos nos Possos $1 A$, $\mathrm{IB}$ e IC. Usando as catōes de pontuaç̄o, perco oo clente que chssitique, 
PASSO 3: PONTUACĀO - AVALLAC̄̄OO INICIAL

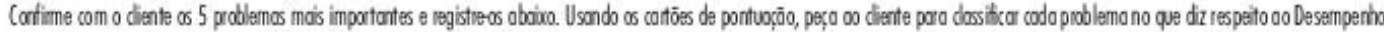

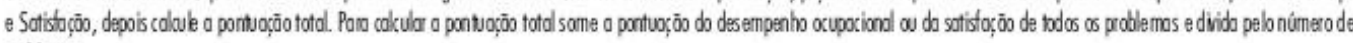
problemes.

PASSO 4: REAVALACĀO

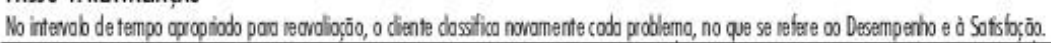

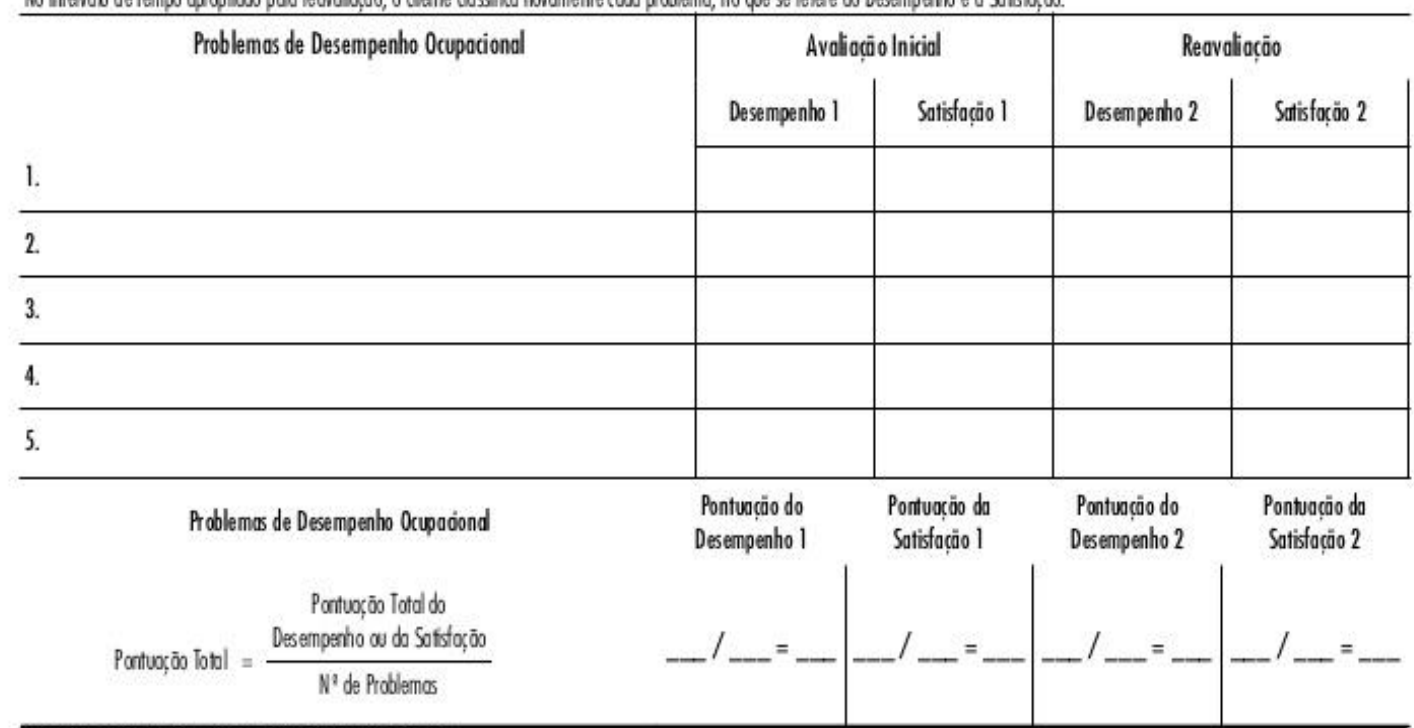

PASSO 5: COMPUTANDO OS ESCORES DE MUDANCA

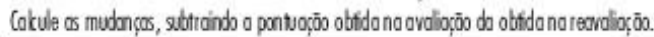

Mudança no Desempenho $=\quad$ Pontuaç̄o do Desempenho 2 - Pontuação do Desempenho 1 $=$

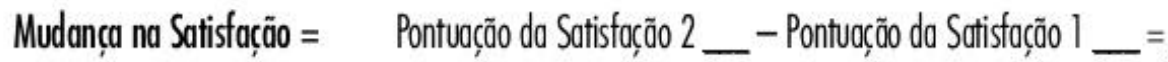

ANOTACÕES ADICIONAIS E OBSERNAÇOEES

Avaliaçäo inioant: 
Escala de importância

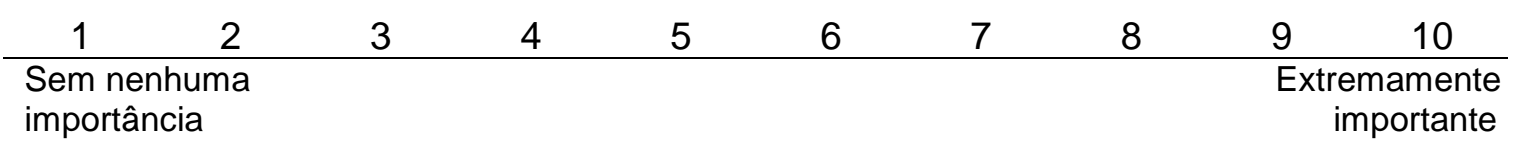

\section{Escala de desemepenho}

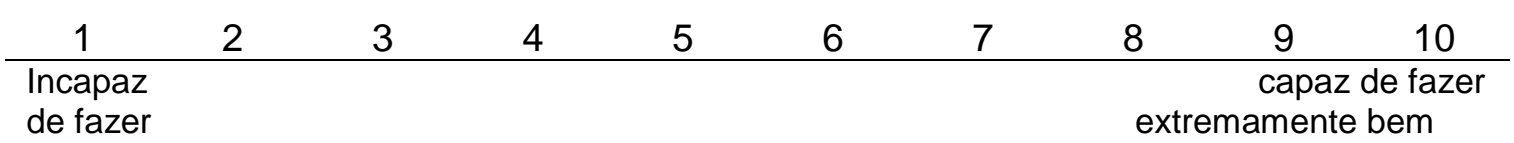

Escala de satisfação

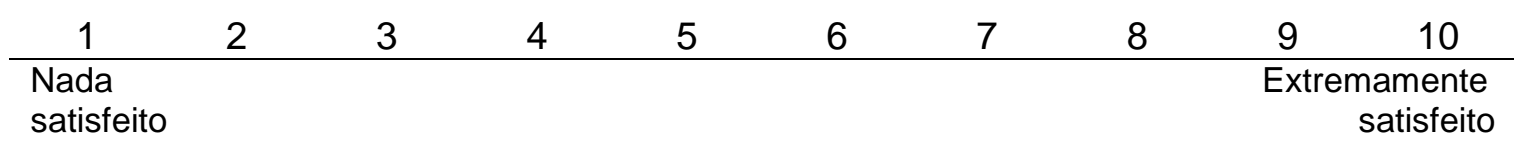




\section{Apêndice}

Apêndice 1. Termo de consentimento livre e esclarecido

HOSPITAL DAS CLÍNICAS DA FACULDADE DE MEDICINA

DE RIBEIRÃO PRETO DA UNIVERSIDADE DE SÃO PAULO

www.hcrp.fmrp.usp.br

\section{TERMO DE CONSENTIMENTO LIVRE E ESCLARECIDO}

Você está sendo convidada para participar, como voluntária, em uma pesquisa. Após ser esclarecida sobre as informações a seguir, no caso de aceitar fazer parte do estudo, assine ao final deste documento, que está em duas vias. Uma delas é sua e a outra é do pesquisador responsável. Você não é obrigada a participar. Em caso de dúvida você pode procurar o Comitê de Ética em Pesquisa do Hospital das Clínicas da Faculdade de Medicina de Ribeirão Preto da Universidade de São Paulo ou pelo telefone (16) 3602-2228.

Título do Projeto: Caracterização do desempenho ocupacional de mulheres portadoras de dor pélvica crônica.

Pesquisador Responsável: Prof. Dr. Omero Benedicto Poli Neto (16) 36022583/2311/0002

Pesquisadores participantes: Prof. Dr. Antônio Alberto Nogueira (16) 36022589/2311, Prof. Dr. Francisco José Candido dos Reis (16) 3602-2589/2311, Prof. Dr. Júlio César Rosa-e-Silva (16) 3602-2311, Terapeuta ocupacional Raquel Verceze Bortolieiro (16) 3602-2581.

1) Este projeto pretende basicamente verificar se a sua condição clínica (dor pélvica crônica) interfere no seu desempenho ocupacional (atividades de trabalho, lazer, cuidados próprios, cuidados de dependentes) e se ele sofre influencia do medo de exercer alguma atividade física ou se interfere na sua qualidade de global. 
2) Sua participação neste estudo será responder verbalmente a um questionário objetivo. Você não precisará responder às questões que não quiser ou que não se sentir confortável e seguro, nem mesmo prosseguir a entrevista se assim o desejar.

3) Você não terá gastos financeiros adicionais. Priorizaremos que suas entrevistas sejam em datas de retorno no próprio ambulatório e durará cerca de 30 minutos. Caso contrário, disponibilizaremos passes de transporte público. Todas as dúvidas referentes ao questionamento poderão ser sanadas pelos entrevistadores ou pelos responsáveis definidos acima.

4) Teremos o compromisso de que você será devidamente orientada com relação ao tema, se isso for de seu interesse.

5) Essa pesquisa não implica em danos para você.

6) Os resultados da pesquisa serão importantes para compreender o quanto a dor pélvica crônica interfere nas atividades ocupacionais das mulheres oriundas da nossa região e, futuramente, traçarmos planos de atuação para minimizar essa interferência. Isso poderá trazer alguma vantagem direta pra você num futuro próximo, através da orientação de medidas para otimizar suas atividades diárias.

7) Você terá a segurança de não ser identificado e ter mantido o caráter confidencial da informação relacionada à sua privacidade.

8) Nos comprometemos a prestar-Ihe informação atualizada durante o estudo, ainda que esta possa afetar a sua vontade de continuar dele participando.

9) Você pode retirar o seu consentimento para participar deste estudo a qualquer momento, inclusive sem justificativas e sem qualquer prejuízo.

10) Você terá a garantia de receber a resposta a qualquer pergunta ou esclarecimento de qualquer dúvida a respeito da pesquisa. Qualquer questão a respeito do estudo ou de sua saúde deve ser dirigida aos responsáveis pelo projeto, designados no início deste termo, o que poderá ser realizada no Ambulatório AGDP que ocorre às $6^{a}$ feiras no período da manhã no balcão 1 verde claro do Hospital das Clínicas da Faculdade de Medicina de Ribeirão Preto, Ambulatório de Ginecologia, ou no Hospital das Clínicas da FMRPUSP (secretaria de pós-graduação $8^{\circ}$ andar) ou pelos telefones de contato informados no início desse termo. O Comitê de Ética em Pesquisa do HCRP 
pode lhe oferecer informações caso você não queira falar com nenhum dos pesquisadores responsáveis por este estudo.

$\mathrm{Eu}$,

, abaixo assinado, concordo em participar do estudo "Caracterização do desempenho ocupacional de mulheres portadoras de dor pélvica crônica", como sujeito. Fui devidamente informada em detalhes pelo(s) pesquisador(es) responsável(is) no que diz respeito ao objetivo da pesquisa, aos procedimentos que serei submetida, aos riscos e benefícios, à forma de ressarcimento no caso de eventuais despesas, bem como à indenização se houver danos decorrentes da pesquisa. Declaro que tenho pleno conhecimento dos direitos e das condições que me foram asseguradas e que posso retirar meu consentimento a qualquer momento, sem que isto leve a qualquer penalidade ou interrupção de meu acompanhamento/ assistência/ tratamento.

Declaro, ainda, que concordo inteiramente com as condições que me foram apresentadas e que, livremente, manifesto a minha vontade de participar desse estudo.

Ribeirão Preto, de de

Assinatura do voluntário

Assinatura do entrevistador/ testemunha. 
Apêndice 2. Carta de aprovação do CEP

Oficio $n^{\circ} 2329 / 2012$

HOSPITAL DAS CLINICAS DA FACULDADE DE MEDICINA DE RIBEIRÃO PRETO DA UNIVERSIDADE DE SÃO PAULO

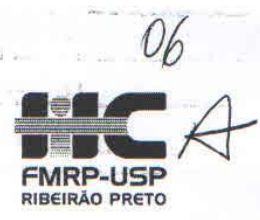

$\mathrm{CEP} / \mathrm{MGV}$

Prezados Senhores,

Ribeirão Preto, 27 de junho de 2012

O trabalho intitulado "CARACTERIZAÇÃo DO DESEMPENHO OCUPACIONAL DE MULHERES PORTADORAS DE DOR PÉlVICA CRÔNICA", foi analisado pelo Comitê de Ética em Pesquisa, em sua $348^{a}$ Reunião Ordinária realizada em $25 / 06 / 2012$, e enquadrado na categoria: APROVADO, bem como o Termo de Consentimento Livre e Esclarecido, de acordo com o Processo HCRP n 9091/2012.

De acordo com Carta Circular $n^{\circ}$ 003/2011/CONEP/CNS, datada de 21/03/2011, o sujeito de pesquisa ou seu representante, quando for o caso, deverá rubricar todas as folhas do Termo de Consentimento Livre $e$ Esclarecido - TCLE - apondo sua assinatura na última do referido Termo; o pesquisador responsável deverá da mesma forma, rubricar todas as folhas do Termo de Consentimento Livre e Esclarecido - TCLE - apondo sua assinatura na última página do referido Termo.

Este Comitê segue integralmente a Conferência Internacional de Harmonização de Boas Práticas Clínicas (IGH-GCP), bem como a Resolução $n^{\circ}$ 196/96 CNS/MS.

Relatório Parcial e o Relatório Final da pesquisa.

Lembramos que devem ser apresentados a este CEP, o Atenciosamente.

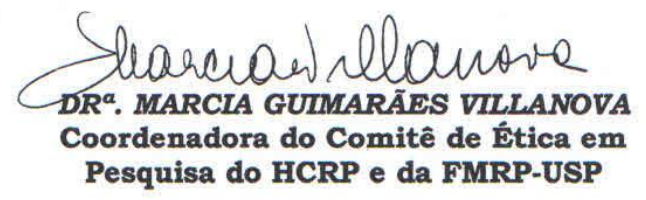

Ilustrissimos Senhores

PROF. DR. OMERO BENEDICTO POLI NETO(Orientador)

RAQUEL VERCEZE BORTOLIEIRO

Depto. de Ginecologia e Obstetricia 
Apêndice 3. Manuscrito

Potenciais intervenções não assistivas da terapia ocupacional no tratamento da mulher com dor pélvica crônica: revisão sistematizada

Raquel Verceze Bortolieiro, Francisco Jose Candido-dos-Reis, Júlio Cesar Rosa-e-Silva, Antônio Alberto Nogueira, Omero Benedicto Poli-Neto.

Departamento de Ginecologia e Obstetrícia. Faculdade de Medicina de Ribeirão Preto, Universidade de São Paulo, Ribeirão Preto, São Paulo, Brasil.

Autor para Correspondência

Omero Benedicto Poli-Neto PhD, Department of Gynecology and Obstetrics, Ribeirão Preto Medical School, University of São Paulo, Ribeirão Preto, SP, Brazil. Address: Hospital das Clínicas da Faculdade de Medicina de Ribeirão Preto da Universidade de São Paulo, Campus Universitário s/n. Monte Alegre. Ribeirão Preto- SP. CEP 14048-900. Brazil. Tel +551636022589, FAX: +551636330946 .

E-mail:

polineto@fmrp.usp.br 


\section{Resumo}

Introdução: Mulheres apresentam dor persistente mais frequentemente que homens. Dentre as condições que cursam com tais sintomas, a dor pélvica crônica é uma das mais frequentes entre mulheres na idade reprodutiva, com impacto negativo direto na vida conjugal, social e profissional. A terapia ocupacional tem se preocupado com fatores físicos, psicossociais e ambientais agravados pela dor, particularmente de autocuidado, lazer e trabalho. Entre as intervenções mais utilizadas, destacam-se a teoria cognitiva comportamental, 0 estabelecimento de metas, o relaxamento e o pacing. Objetivo: Este estudo tem como objetivo revisar os ensaios clínicos sobre intervenções não assistivas da terapia ocupacional em pacientes com dor crônica com potencial de aplicabilidade à população de mulheres com dor pélvica crônica. Métodos: Busca bibliográfica nos bancos de dados Pubmed e Scopus foi realizada com a utilização dos descritores: ["occupational therapy" or "pacing" or "relax" or "goal"” or "cognit*" or "exerc"] e ["chronic pain" or "persistente pain"]. Todos os artigos selecionados foram obtidos na íntegra e foram avaliados independentemente por dois pesquisadores. Para avaliar a qualidade dos estudos clínicos, foi utilizada a escala de Jadad que pontua os estudos com notas entre 0 a 5. Resultados: Foram encontrados 264 artigos, dos quais foram quatro foram elegíveis. As técnicas identificadas como possíveis intervenções no manejo da dor pélvica crônica foram: pacing, tratamento conservador e enfrentamento. Conclusão: As informações disponíveis em bases de dados internacionais são escassas e com um grau muito heterogêneo de qualidade. Ainda assim, acreditamos ser factível a proposição dessas intervenções a mulheres com dor pélvica crônica.

Palavras-chave: Dor pélvica crônica, Terapia Ocupacional, Dor crônica e Intervenção. 


\section{Abstract}

Introduction: Women have persistent pain more often than men, among the disorders that present with chronic pain, chronic pelvic pain is the most common among women of reproductive age, with direct impact on marital life, social and professional woman. Occupational therapy has been concerned with physical, psychosocial and environmental factors aggravated by pain, particularly selfcare, leisure and work. Among the most commonly used interventions, it highlights the cognitive behavioral theory, goal setting, relaxation and pacing. Objective: This study aims to review the clinical trials on non assistive intervention of occupational therapy in patients with chronic pain with potential applicability to the population of women with chronic pelvic pain. Methodology: Conducted by bibliographic search databases PUBMED and SCOPUS, using the descriptors: ["occupational therapy" or "pacing" or "relax *" or "goal *" or "* Cognit" or "subs *"] and ["chronic pain" or "persistent pain"]. All selected articles were obtained in full and were independently evaluated by researchers. To assess the quality of clinical studies, we used the Jadad scale et al, (1996) points out that the studies with notes from 0 to 5. Results: Found 4 eligible items found in 264 , the techniques as possible interventions in the management the identified chronic pain were: pacing, conservative treatment and coping. Conclusion: The information available in international databases are scarce and with a very heterogeneous level of quality. We believe it is perfectly feasible that these interventions are proposed to women with chronic pelvic pain, since all can be applied in this type of patient.

Keywords: Chronic Pelvic Pain, Occupational Therapy, Chronic pain and Intervention. 


\section{Introdução}

Mulheres apresentam dor persistente mais frequentemente que homens (1). Dentre as condições que cursam com dor crônica, a dor pélvica crônica é uma das mais frequentes entre mulheres na idade reprodutiva (2), com impacto negativo direto na sua vida conjugal, social e profissional $(3,4)$. A prevalência estimada desta condição é de aproximadamente $4 \%$ no mundo $(5,6)$, embora no Brasil estudos mostram que seja próxima de $11 \%$ (7). O impacto da dor no desempenho econômico das mulheres afeta diretamente a atividade econômica domiciliar, visto que hoje elas são responsáveis por $50 \%$ ou mais da renda familiar (10).

A terapia ocupacional tem se preocupado com fatores físicos, psicossociais e ambientais agravados pela dor, particularmente nas esferas de autocuidado, lazer e trabalho. Programas de treinamento ocupacional têm se mostrado eficazes na orientação e reabilitação de pacientes portadores de dor crônica desde a década de 80 (11, 12). Entre as intervenções mais utilizadas, destacam-se a teoria cognitiva comportamental, o estabelecimento de metas, o relaxamento e o pacing (13). Embora a dor pélvica crônica seja um problema de saúde pública e apresente consideráveis repercussões ocupacionais, não encontramos na literatura nenhum estudo diretamente ligado às intervenções da terapia ocupacional nesse campo. E, dentro de um contexto multidisciplinar, a International Association for Study of Pain (IASP) recomenda a inclusão do terapeuta ocupacional na equipe assistencial (14). Baseado nestas considerações, este estudo tem como objetivo revisar os ensaios clínicos sobre intervenções não assistivas da terapia ocupacional em pacientes com dor 
crônica com potencial de aplicabilidade à população de mulheres com dor pélvica crônica. 


\section{Métodos}

\section{$\underline{\text { Critérios de elegibilidade }}$}

Foram considerados elegíveis estudos na língua inglesa que descreveram as intervenções do terapeuta ocupacional em sujeitos com dor crônica não oncológica em adultos, independente do sexo e classe da população estudada. Os artigos que utilizaram tecnologias assistivas como forma de intervenção não foram considerados elegíveis. Além disso, os que não apresentaram ou não descreveram a técnica utilizada, bem como, o diagnóstico ou doença que estava sendo tratada não foram elegíveis. Artigos de revisão e guidelines foram lidos na íntegra, porém não foram incluídos na análise. Toda lista de referências bibliográficas foi explorada a fim de ampliar a busca de informações.

\section{Fontes de informação e busca}

Foi realizada uma busca nas bases de dados Pubmed e Scopus, com a utilização dos descritores: ["occupational therapy" or "pacing" or "relax" or "goal" or "cognit" or "exerc"] e ["chronic pain" or "persistente pain"], no qual foi investigado no título e no abstract se continham os descritores. O período de busca realizado foi nos últimos 20 anos (1994 - 2014).

Seleção do estudo

Todos os artigos selecionados foram obtidos na íntegra e foram avaliados independentemente pelos pesquisadores RVB e OBPN. Eventuais dúvidas foram sanadas em uma reunião de consenso.

\section{$\underline{\text { Avaliação da qualidade da informação dos estudos elegíveis }}$}

Para avaliar a qualidade dos estudos clínicos, foi utilizada a escala de Jadad et al., (1996) que pontua os estudos com notas entre 0 a 5 . Essa escala avalia 
características como randomização, cegamento e descrição da perda amostral. Os estudos com avaliação $\leq 2$ foram classificados como de baixa qualidade. Processo de coleta de dados e síntese dos resultados Foram encontrados um total de 264 artigos. Foram eliminados 171 artigos que não esclareceram o profissional que fazia a intervenção ou o tipo de intervenção utilizada e 23 sendo referências e/ou citações. Setenta artigos foram selecionados e lidos na íntegra. Destes, 66 foram descartados, 2 artigos por serem guidelines, 17 revisões bibliográfica e 47 artigos de equipe multidisciplinar (os artigos deste item foram descartados por não descreverem o tipo de intervenção que a terapia ocupacional utilizou dentro da abordagem multidisciplinar e os resultados apresentados foram em conjunto ao trabalho de toda a equipe). Foram considerados elegíveis apenas quatro artigos: (1) "A prospective randomized controlled trial comparing occupational therapy with home-based exercises in conservative treatment of rotator cuff tears."(15), (2) "Effects of a tailored activity pacing intervention on pain and fatigue for adults with osteoarthritis."(16), (3) "Positive affect mediates the relationship between pain-related coping efficacy and interference in social functioning. The journal of pain : official journal of the American Pain Society" (17) e (4) "Defying aches and revaluating daily doing: occupational perspectives on adjusting to chronic pain"(18). A figura 1 apresenta o fluxo de seleção dos artigos. Os artigos selecionados estão dispostos na tabela 1, onde estão detalhados. Os resultados obtidos serão discutidos a seguir. 


\section{$\underline{\text { Resultados e discussão }}$}

Foram identificadas três técnicas diferentes: tratamento não cirúrgico, pacing e enfrentamento. As definições das técnicas, as formas com que elas foram realizadas e os resultados de cada artigo serão discutidos individualmente.

O artigo "A prospective randomized controlled trial comparing occupational therapy with home-based exercises in conservative treatment of rotator cuff tears." mostra o tratamento não cirúrgico em pacientes que apresentam dor crônica, devido lesão no manguito rotador. $O$ tratamento não cirúrgico, como o próprio nome diz, é aquele que não utiliza método cirúrgico, fazendo uso de medicamentos, terapias, entre outros. Nesse tipo de técnica o tratamento utilizado é o fortalecimento de musculatura, amplitude de movimento, uso de crioterapia (terapia com gelo), hipertermoterapia (terapia com calor), aumento de resistência, entre outros.

O autor justifica o uso desse tratamento não cirúrgico com o objetivo de restabelecer o controle neuromuscular do ombro, além de realizar a manutenção fisiológica do local, para redução de dor. 38 pacientes com lesão no manguito rotador, sem histórico de cirurgias e com dor por mais de 3 meses foram incluídos. Os sujeitos foram randomizados em dois grupos, um para atendimento de terapia ocupacional e outro com uma cartilha que continham os exercícios para realizar as atividades em domicilio, os exercícios que os pacientes realizaram apresentavam os mesmos objetivos, o autor afirma que foram utilizados exercícios que incluem o fortalecimento, aumento da amplitude de movimento, flexibilidade, alongamento, terapia manual, entre outras modalidades; em ambos os grupos a duração dos exercícios e a forma de executar foram iguais. Os terapeutas que realizaram a intervenção não sabiam 
sobre a pesquisa (blinding). O desfecho avaliado foi a melhora da dor através da escala analógica visual de dor. Os autores aplicaram duas avaliações (VAS e EQ-5D VAS) antes e após a intervenção em cada grupo, as duas avaliações mostram uma diminuição da dor nos dois grupos estudados (15).

Em nossa revisão bibliográfica encontramos uma revisão de 2006 com o objetivo de mensurar a qualidade da técnica "tratamento não cirúrgico" na melhora da dor em pacientes com lesão no manguito rotator, o artigo revela uma variação na melhora da dor entre os artigos analisados, de $33 \%$ a $90 \%$, o autor explica que essa variação é decorrente de fatores como idade, características individuais e critérios utilizados para a mensuração dos resultados, porém chega à conclusão que a técnica traz uma melhora na dor, além do fortalecimento da musculatura, tornando a articulação mais estável e funcional (19).

Sendo assim, dentro do propósito de nossa pesquisa esse tipo de intervenção poderia ser utilizada em mulheres portadoras de dor pélvica crônica. Tem sido mostrado que mulheres com essa condição possuem alterações de postura $(20,21)$ significativas que poderiam advir de comprometimento secundário do sistema musculoesquelético. O fortalecimento dos músculos envolvidos poderia auxiliar no reestabelecimento funcional dos mesmos e minimizar os agravos, particularmente aqueles associados geração de dor.

O segundo artigo "Effects of a tailored activity pacing intervention on pain and fatigue for adults with osteoarthritis." apresenta o tratamento pacing direcionado como alternativa para alivio de dor. O autor define pacing como uma atividade de estimulação através de estratégias de planejamento entre atividades e 
intervalos de descanso, acorrendo uma segmentação das tarefas. Além disso, o autor utiliza o termo pacing direcionado, que é definido como uma atividade adaptada de estimulação abordando padrões e sintomas individuais como base na atividade. $\mathrm{O}$ autor defende o uso do pacing direcionado com base em seus trabalhos anteriores, por ter encontrado uma variação de dor e fadiga muscular muito alta entre os participantes, além de ser uma atividade natural e préplanejada apresentando um resultado de reação do individuo aos seus sintomas (16).

A estratégia pacing ainda não apresenta uma definição clara e bem definida. Em um artigo internacional pacing foi definido como "uma estratégia de participação ativa, onde os indivíduos se tornam mais eficazes através de atividades com o intuito de equilibrar o tempo gasto em atividade e descanso com a finalidade de alcançar o aumento da função" (22), o autor da definição esclarece que a atividade utilizada é de escolha do paciente, e na maioria das vezes são atividades manuais (pintura, jogos, entre outros).

$\mathrm{Na}$ literatura nacional encontramos uma citação que defini pacing como uma atividade relacionada ao conceito do ciclo de atividade e repouso e é descrito na forma de alternação de períodos de exercício de atividades moderadas com pequenos períodos de repouso(23).

Participaram do estudo 32 pessoas de idades entre 50-80 anos, apresentavam osteoartrite no joelho ou quadril e autorrelato de dor por pelo menos 3 meses e pontuação acima de 4 dos 5 itens do questionário de dor WOMAC (Western Ontario e McMaster Universities Osteoarthritis Index). Os 32 participantes foram estratificados por idade e sexo e randomizados em 2 grupos, 1-pacing 
geral e 2-pacing direcionado. Ambos os grupos receberam instruções gerais, chamado de "educação especifica" sobre estimulação pacing. Posteriormente o terapeuta discutiu no grupo 1 os princípios gerais da atividade de estimulação (atividades de pré-planejamento, e alternância da atividade com o descanso e a introdução do método no dia-a-dia dos indivíduos) e no grupo 2 o terapeuta realizou a sessão com base nos sintomas que os pacientes relataram e o progresso individual com a atividade. O período de coleta foi desde o início, meio e fim das 10 semanas de acompanhamento; os testes utilizados foram WOMAC questionário dor, BFI (Brief Fatigue Inventory) questionário fadiga, Six Minute Walk Test e Timed Up and Go test para função física, e um acelerômetro, para monitoramente durante 5 dias, que apresenta uma contagem de picos de movimentos e intensidade. Em ambos os grupos o resultado de dor medido pelo WOMAC diminuiu pouco dentro do esperado, porém apresentou uma pontuação de dor maior antes da intervenção; o questionário BFI mostra que a fadiga em ambos os grupos melhorou, porém o grupo 2 apresentou uma melhora maior; além disso a interferência da fadiga na atividade foi mensurada, o grupo 2 apresentou uma queda na interferência muito discrepante, sendo que anterior a intervenção ambos os grupos apresentavam um resultado de interferência próximo. O artigo coloca que como o resultado de dor, apesar de pequeno, apresentou uma queda, a atividade pacing, independente pacing geral ou direcionado, podem interferir na diminuição da dor, os registros do acelerômetro e da função física foram utilizados para complementar os relatórios do terapeuta sobre o individuo afim do direcionamento futuro dos atendimentos; além disso ele comenta sobre a importância de realizar a pesquisa em um grupo maior de pacientes e o uso de 
mais terapeutas ocupacionais para aumentar a eficácia na intervenção e inserir um grupo controle (16).

Como podemos observar o segundo artigo nos trás a intervenção pacing em pacientes com osteoartrite em joelho ou quadril, o artigo nos revela que há uma diminuição da dor e fadiga em pacientes que participaram da pesquisa. Pensando em nosso objetivo o pacing geral ou direcionado seria uma possível intervenção em mulheres com dor pélvica crônica, mas é importante discutir aqui a dificuldade dos pesquisadores em realizar a intervenção no âmbito clinico, o que para nós, terapeutas ocupacionais, é de extrema importância, uma vez que nossa profissão é baseada em evidencias; sendo assim sugerese que mais artigos sejam publicados utilizando a intervenção pacing.

Os artigos "Positive affect mediates the relationship between pain-related coping efficacy and interference in social functioning" e "Defying aches and revaluating daily doing: occupational perspectives on adjusting to chronic pain" apresentam como forma de intervenção o enfrentamento. O enfrentamento tem por definição "todos os esforços cognitivos e comportamentais que mudam constantemente, para lidar com exigências (...) avaliadas como sobrecarga ou excedendo os recursos dos indivíduos" (24).

O enfrentamento tem sua base teórica a partir da teoria cognitivacomportamental. Essa teoria surgiu a partir de 1956, onde Beck estudando as abordagens de Freud se indagou com novos pensamentos divergentes aos da psicanalise. Beck observou que pacientes deprimidos se mostravam com pensamentos negativos e junto à sua equipe realizou alguns experimentos a fim de mudar ou gerar outro tipo de condição ou pensamento através de 
estímulos diferentes do que o indivíduo experimentou no passado, para obter uma melhora no quadro depressivo desses pacientes (25). Esse conceito é engajado pelo fato de que as crenças, as atitudes, os valores e os comportamentos relacionados à saúde em geral e, em especial, à dor são culturalmente adquiridos e podem ser modificados (26). Na teoria, o indivíduo aprende a enfrentar, controlar e reduzir a dor empregando estratégias de coping, ou enfrentamento, e de autogerenciamento do cotidiano sob novas bases de sua relação corporal com o mundo (27).

Portnoi, Nogueira \& Maeda, em seu artigo sobre o enfrentamento da dor crônica, afirmam que a "aquisição, desenvolvimento ou aprimoramento de recursos de enfrentamento da dor crônica pode ser mais importante do que a criação e execução das estratégias propriamente ditas"(28), ou seja, para o paciente é melhor aprender a conviver com a dor ao invés de iniciar um tratamento para realizar suas atividades, ele sugere que a realização das atividades virá como consequência do enfrentamento da dor.

O enfrentamento apresenta duas vertentes, antes de comentá-las é importante sabermos que o enfrentamento baseia-se como uma hierarquia do comportamento adaptativo, dos mais imaturos aos mais sofisticados, numa relação entre saúde e doença. Há uma relação intrínseca entre as estratégias e os resultados de enfrentamento. Os resultados devem ser vistos como uma reação intencional do sujeito perante o estresse percebido, ou seja, o objetivo do enfrentamento constitui-se na intenção de uma resposta e é geralmente orientada para a redução do estresse. Dentro do enfrentamento existem duas vertentes de atuação, a primeira objetiva a parte emocional, que é definido como um esforço para diminuir a sensação desagradável de um estado de 
estresse, tendo como objetivo alertar o indivíduo em eventos estressantes; e a segunda, por sua vez, é focada no problema, por um esforço para atuar diretamente na situação que deu origem ao estresse, para alterar o problema existente na relação entre a pessoa e o ambiente que está causando tensão (29).

O terceiro artigo "Positive affect mediates the relationship between pain-related coping efficacy and interference in social functioning." mostra a questão das emoções positivas em relação a emoções negativas; para isso o autor utilizou o questionário Treatment Outcomes in Pain Survey (TOPS), um questionário de 120 itens que avalia a saúde geral, o estado de humor, a intensidade da dor, percepção de controle, e a percepção da dor na interferência de seu funcionamento, esta medida de autorrelato incorpora e expande elementos do SF-36 e outras escalas de dor; é um questionário subjetivo com um resultado numérico; e o questionário Numerical Rating Scale (NRS) também foi utilizado para avaliar a intensidade da dor que classifica a dor de 0(sem dor)-6 (pior dor imaginável) para classificar a dor década individuo nas ultimas 4 semanas. 0 autor separou os participantes com base no nível de educação, renda, intensidade média de dor, o resultado do artigo revela que pacientes com dor crônica que apresentam mais emoções positivas que negativas podem desempenhar um papel importante na relação do indivíduo no controle da dor, enfrentamento da dor e funcionamento social, ou seja, esses pacientes apresentam uma melhora da sensação da dor (17).

O último artigo "Defying aches and revaluating daily doing: occupational perspectives on adjusting to chronic pain" apresenta questões sobre experiências de ocupações diárias, como o indivíduo lida com a dor e a sua 
sensação de bem-estar, e o que espera do futuro. O autor interviu de forma com que os entrevistados refletissem sobre suas ocupações diárias e as classificassem (autoavaliação) em duas categorias (1) Altering doing processes e (2) Altering values, onde a partir delas apareciam quatro subcategorias: (1.1) slowing down pace and performance, (1.2) Opening uo for improvisation, (1.3) Daydreaming e (1.4) Prioritising pain-defiers e (2.1) Adopting new values, (2.2) Acceptgin social restrictions and upgrading loneliness, (2.3) finding non-material values e (2.4) Appreciating the ordinary, através dessas subcategorias os indivíduos puderam se expressar e assim apresentar suas dificuldades e facilidades. Foi possível observar no estudo como os pacientes lidam com as dificuldades encontradas e as estratégias que os mesmos utilizam para lidar com a dor, como por exemplo: o esforço e capacidade de adaptação às circunstâncias diárias foram essenciais para o enfrentamento dos pacientes para manter seu bem estar; também foi possível observar que os pacientes declaram a diminuição do ritmo e desempenho de suas ocupações diárias, mas também relatam que a satisfação em realizar uma atividade do início ao fim, mesmo sendo pequenas ou rápidas, aumentou; essa satisfação pode ser associada a outro resultado encontrado, a adesão de novos valores, esses pacientes apresentam muito o "sonhar acordado" (imaginar algo que será prazeroso), o fato de realizar uma atividade do início ao fim é um avanço dentro daquilo que ele pensa que é prazeroso, outro ponto que foi possível observar é o relato de que ocupações que desafiam a dor trás algumas sensações e experiências que trazem confiança e esperança para o futuro, apesar da dor. (18). 
Em ambos os estudos podemos observar que o paciente apresenta, após a intervenção, uma percepção diferenciada da dor, os dois artigos trazem maneiras distintas de utilizar o enfrentamento, em um artigo o autor realiza a intervenção através de como o individuo percebe a dor e como suas emoções afetam seu dia a dia; já no outro artigo o autor utiliza a reflexão do próprio individuo perante a sua dor, conseguindo controlar e enfrentar melhor a situação e assim realizar as atividades ocupacionais de uma forma mais significativa. O interessante para nosso estudo é que este tipo de técnica possibilita que o paciente, através do terapeuta, encontre caminhos para enfrentar a dor dentro do que realmente é importante para indivíduo, e assim adaptar-se perante suas limitações. O individuo é capaz de aprimorar seu enfrentamento na dor e assim estabelecer caminhos e mudanças para sua convivência com a mesma. Desta forma esse tipo de intervenção se encaixa ao nosso objetivo. 
Tabela 1. Intervenção de terapia ocupacional em pacientes com dor crônica

\begin{tabular}{|c|c|c|c|c|c|c|c|c|}
\hline Autor & País & Periódico & Ano & $\begin{array}{l}\text { Grupo de } \\
\text { intervenção }\end{array}$ & Duração & $\begin{array}{l}\text { Instrumentos } \\
\text { de avaliação }\end{array}$ & Resultados & $\begin{array}{l}\text { Escore de } \\
\text { Qualidade }\end{array}$ \\
\hline Krischak, G. et al & Alemanha & $\begin{array}{l}\text { J. Shoulder } \\
\text { Elbow }\end{array}$ & 2013 & $\begin{array}{l}\text { 1-Tratamento } \\
\text { não cirúrgico } \\
\text { T.O. } \\
\text { 2-Cartilha }\end{array}$ & 8 semanas & $\begin{array}{l}\text { "VAS } \\
\text { EQ-5D }\end{array}$ & $\begin{array}{l}\text { Sem } \\
\text { melhora da } \\
\text { dor }\end{array}$ & 5 \\
\hline Murphy, S.L et al & USA & $\begin{array}{l}\text { American } \\
\text { Journal } \\
\text { Occupational } \\
\text { Therapy }\end{array}$ & 2010 & $\begin{array}{l}\text { 1-Pacing } \\
\text { 2-Pacing } \\
\text { direcionado }\end{array}$ & 10 semanas & $\begin{array}{l}\text { **BFI/WOMAC/ } \\
\text { Teste de } \\
\text { caminhada/ } \\
\text { Timed Up and } \\
\text { Go } \\
\text { Test/Actiwatch- } \\
\text { Score }\end{array}$ & $\begin{array}{l}\text { Melhora da } \\
\text { dor }\end{array}$ & 4 \\
\hline $\begin{array}{l}\text { Park, S.H.; Sonty, } \\
\text { N. }\end{array}$ & $\begin{array}{l}\text { Estados } \\
\text { Unidos }\end{array}$ & $\begin{array}{l}\text { The Journal } \\
\text { of Pain }\end{array}$ & 2010 & Enfrentamento & 1 entrevista & $\begin{array}{l}* * * \text { TOPS } \\
\text { NRS }\end{array}$ & $\begin{array}{l}\text { Melhora da } \\
\text { dor }\end{array}$ & 1 \\
\hline $\begin{array}{l}\frac{\text { Persson D, }}{\text { Andersson I, }} \\
\text { Eklund M. }\end{array}$ & Suécia & $\begin{array}{l}\text { Scand J of } \\
\text { Occupat } \\
\text { Therapy }\end{array}$ & 2011 & Enfrentamento & $\begin{array}{l}1 \text { entrevista } \\
\text { (45-60 min.) }\end{array}$ & $\begin{array}{l}\text { Entrevista } \\
\text { desenvolvida } \\
\text { pelo } \\
\text { pesquisador }\end{array}$ & $\begin{array}{l}\text { Melhora da } \\
\text { dor }\end{array}$ & 2 \\
\hline
\end{tabular}

*VAS: Visual Analogue Scale, EQ-5D: EuroQol questionnaire/ BFI: Brief Fatigue Inventory, PROMIS: Reported Outcomes Measurement,WOMAC: Western Ontario and McMaster Universities Osteoarthritis Index/ TOPS: Tratment outcomes in pain survey, NRS: Numerical rating scale. 


\section{Conclusão}

Neste artigo identificamos as atividades ocupacionais de pacing, tratamento conservador e enfrentamento como possíveis intervenções no manejo da dor crônica.

Além disso, nossa revisão mostra que as informações disponíveis em bases de dados internacionais sobre as intervenções da terapia ocupacional em sujeitos com dor crônica ainda são escassas e com um grau muito heterogêneo de qualidade. Considerando a plausibilidade da intervenção e seu efeitos sobre a dor e a própria vida do sujeito, julgamos necessário o delineamento sistematizado de mais estudos sobre o tema com urgência. De qualquer modo, acreditamos ser perfeitamente factível que essas intervenções sejam propostas a mulheres com dor pélvica crônica, uma vez que todas podem ser aplicadas nesse tipo de paciente. Destacamos aqui, a partir de nosso conhecimento clínico, que a técnica de enfrentamento seria a mais adequada inicialmente, pois ela faz com que o paciente aprenda a enfrentar a dor crônica e conhecer seus limites em relação a dor; e posteriormente facilitar um estabelecimento de metas a serem alcançadas objetivando seus interesses, onde as intervenções de pacing e tratamento conservador poderiam ser aplicadas de uma forma mais adequada. 
Fluxograma

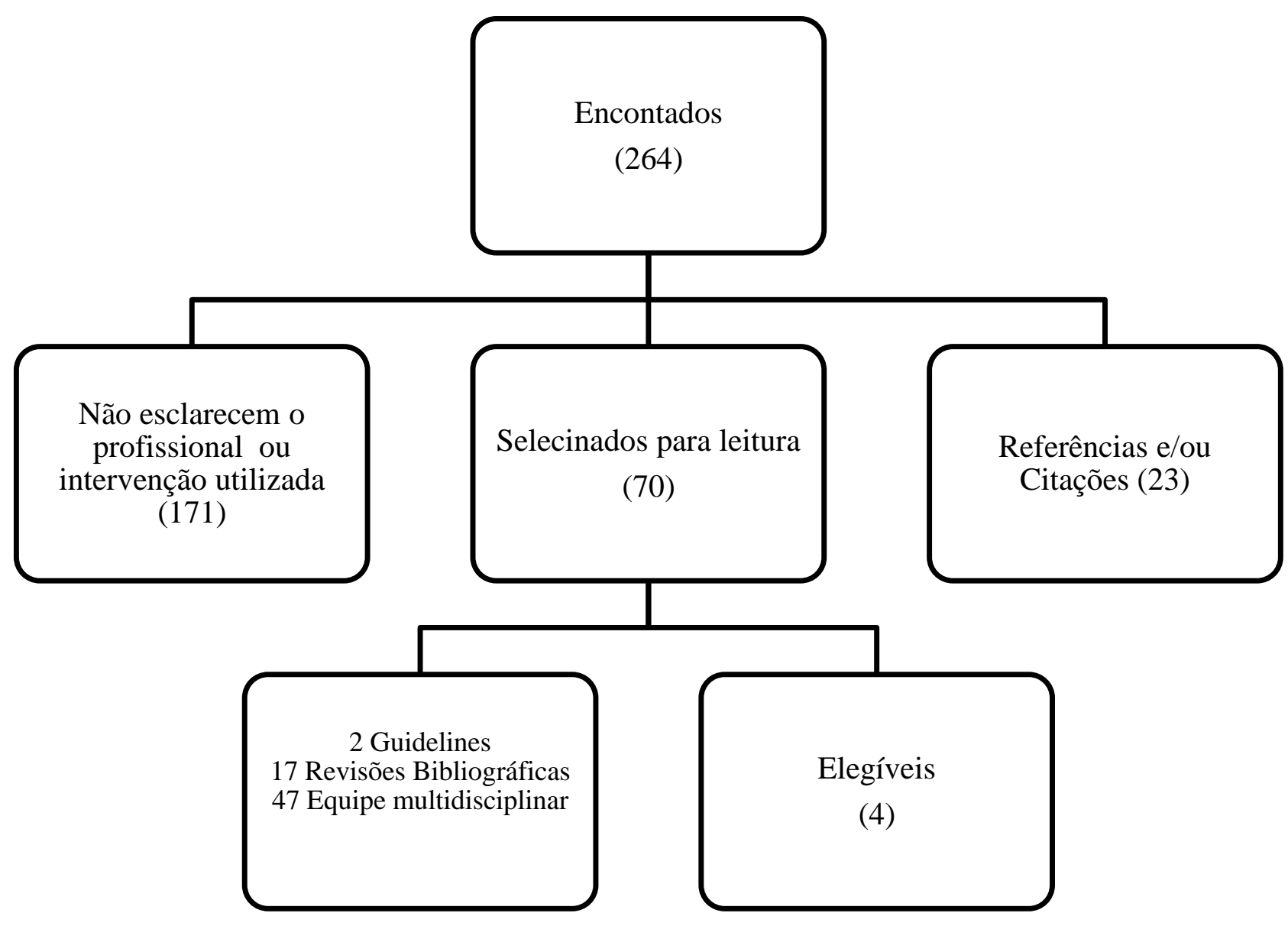


Bibliografia

1. Tsang A, Von Korff M, Lee S, Alonso J, Karam E, Angermeyer MC, et al. Common chronic pain conditions in developed and developing countries: gender and age differences and comorbidity with depression-anxiety disorders. J Pain. 2008;9(10):883-91.

2. Bulletins--Gynecology ACoP. ACOG Practice Bulletin No. 51. Chronic pelvic pain. Obstetrics and gynecology. 2004;103(3):589-605.

3. Romao AP, Gorayeb R, Romao GS, Poli-Neto OB, dos Reis FJ, Rosa-eSilva JC, et al. Chronic pelvic pain: multifactorial influences. Journal of evaluation in clinical practice. 2011;17(6):1137-9.

4. Souza PP, Romao AS, Rosa-e-Silva JC, Reis FC, Nogueira AA, PoliNeto OB. Qualitative research as the basis for a biopsychosocial approach to women with chronic pelvic pain. Journal of psychosomatic obstetrics and gynaecology. 2011;32(4):165-72.

5. Latthe P, Latthe M, Say L, Gulmezoglu M, Khan KS. WHO systematic review of prevalence of chronic pelvic pain: a neglected reproductive health morbidity. BMC public health. 2006;6:177.

6. Grace VM, Zondervan KT. Chronic pelvic pain in New Zealand: prevalence, pain severity, diagnoses and use of the health services. Aust N Z J Public Health. 2004;28(4):369-75.

7. Silva GPOG, Nascimento AL, Michelazzo D, Alves-Junior FF, Rocha MG, Rosa-e-Silva JC, et al. High prevalence of chronic pelvic pain in women in Ribeirao Preto, Brazil and direct association with abdominal surgery. Clinics (Sao Paulo). 2011;66(8):1307-12.

8. Mathias SD, Kuppermann M, Liberman RF, Lipschutz RC, Steege JF. Chronic pelvic pain: prevalence, health-related quality of life, and economic correlates. Obstet Gynecol. 1996;87(3):321-7.

9. Stones RW, Selfe SA, Fransman S, Horn SA. Psychosocial and economic impact of chronic pelvic pain. Baillieres Best Pract Res Clin Obstet Gynaecol. 2000;14(3):415-31.

10. Fleck AC, Wagner A. A mulher como a principal provedora do sustento econônomico familiar. Psicologia em estudo. 2003;8:31-8.

11. Borrelli EF, Warfield CA. Occupational therapy for chronic pain. Hosp Pract (Off Ed). 1986;21(8):36K-R, 7.

12. Paquette $S$. Return to work with chronic low back pain: using an evidence-based approach along with the occupational therapy framework. Work. 2008;31(1):63-71.

13. van Huet $H$, Innes E, Stancliffe R. Occupational therapists perspectives of factors influencing chronic pain management. Australian occupational therapy journal. 2013;60(1):56-65.

14. Shannon E. Reflections on clinical practice by occupational therapists working in multidisciplinary pain management programmes in the UK and the USA. Australian Occupational Therapy Journal. 2002;49(1):48-52.

15. Krischak G, Gebhard F, Reichel H, Friemert B, Schneider F, Fisser C, et al. A prospective randomized controlled trial comparing occupational therapy with home-based exercises in conservative treatment of rotator cuff tears. 
Journal of shoulder and elbow surgery / American Shoulder and Elbow Surgeons [et al]. 2013;22(9):1173-9.

16. Murphy SL, Lyden AK, Smith DM, Dong Q, Koliba JF. Effects of a tailored activity pacing intervention on pain and fatigue for adults with osteoarthritis. Am J Occup Ther. 2010;64(6):869-76.

17. Park $\mathrm{SH}$, Sonty $\mathrm{N}$. Positive affect mediates the relationship between pain-related coping efficacy and interference in social functioning. J Pain. 2010;11(12):1267-73.

18. Persson D, Andersson I, Eklund M. Defying aches and revaluating daily doing: occupational perspectives on adjusting to chronic pain. Scand J Occup Ther. 2011;18(3):188-97.

19. Lemos LA, Lessa P. Principios do tratamento conservador na lesão maciça do manguito rotador. Salvador: Universidade Católica; 2006.

20. Montenegro ML, Mateus-Vasconcelos EC, Rosa ESJC, Dos Reis FJ, Nogueira AA, Poli-Neto OB. Postural changes in women with chronic pelvic pain: a case control study. BMC musculoskeletal disorders. 2009;10:82.

21. Tu FF, As-Sanie S, Steege JF. Prevalence of pelvic musculoskeletal disorders in a female chronic pelvic pain clinic. J Reprod Med. 2006;51(3):1859.

22. Jamieson-Lega K, Berry R, Brown CA. Pacing: a concept analysis of the chronic pain intervention. Pain Res Manag. 2013;18(4):207-13.

23. CARLO MMRP, ELUI VMC, PACKER MP. Terapia ocupacional e atenção a pacientes com dor não-oncológica. In: Roca, editor. Dor e cuidados paliativo-terapia ocuapcional e interdisciplinaridade. São Paulo: $1^{\circ}$ edição; 2008. p. 167-90.

24. Lazarus R, Folkman S. Stress, appraisal, and coping. New York: Springer; 1984.

25. Beck A, Alford B. O poder integrador da terapia cognitiva2000.

26. Pimenta C. Dor crônica, terapia cognitiva comportamental e o enfermeiro. Revista Psiquiátrica Clínica. 2001;28(6):288.

27. Nunes C. Dor neuromusculoesquelética. Terapia ocupacional: fundamentaçao \& prática. Koogan G. ed. Rio de Janeiro2011. p. 258-70.

28. Portnoi AG, Nogueira M, Maeda FL. O enfrentamento da dor. Porto Alegre: Artmed; 2008.

29. NUNES CMP. Dor neuromusculoesquelética. In: Koogan G, editor. Terapia Ocupacional: fundamentação \& prática. Rio de Janeiro2011. p. 258 70. 